\title{
MAX-DOAS tropospheric nitrogen dioxide column measurements compared with the Lotos-Euros air quality model
}

\author{
T. Vlemmix ${ }^{1}$, H. J. Eskes ${ }^{2}$, A. J. M. Piters ${ }^{2}$, M. Schaap ${ }^{3}$, F. J. Sauter ${ }^{4}$, H. Kelder ${ }^{5}$, and P. F. Levelt ${ }^{2,1}$ \\ ${ }^{1}$ Dept. Geoscience \& Remote Sensing, Delft University of Technology, Delft, the Netherlands \\ ${ }^{2}$ Royal Netherlands Meteorological Institute, KNMI, De Bilt, the Netherlands \\ ${ }^{3}$ TNO Dept. Climate, Air and Sustainability, Utrecht, the Netherlands \\ ${ }^{4}$ National Institute for Public Health and the Environment, Bilthoven, the Netherlands \\ ${ }^{5}$ Dept. of Applied Physics, Eindhoven University of Technology, Eindhoven, the Netherlands \\ Correspondence to: T. Vlemmix (t.vlemmix@tudelft.nl)
}

Received: 2 September 2011 - Published in Atmos. Chem. Phys. Discuss.: 26 October 2011

Revised: 2 December 2014 - Accepted: 11 December 2014 - Published: 6 February 2015

\begin{abstract}
A 14-month data set of MAX-DOAS (Multi-Axis Differential Optical Absorption Spectroscopy) tropospheric $\mathrm{NO}_{2}$ column observations in De Bilt, the Netherlands, has been compared with the regional air quality model LotosEuros. The model was run on a $7 \times 7 \mathrm{~km}^{2}$ grid, the same resolution as the emission inventory used. A study was performed to assess the effect of clouds on the retrieval accuracy of the MAX-DOAS observations. Good agreement was found between modeled and measured tropospheric $\mathrm{NO}_{2}$ columns, with an average difference of less than $1 \%$ of the average tropospheric column $\left(14.5 \cdot 10^{15}\right.$ molec $\left.\mathrm{cm}^{-2}\right)$. The comparisons show little cloud cover dependence after cloud corrections for which ceilometer data were used. Hourly differences between observations and model show a Gaussian behavior with a standard deviation $(\sigma)$ of $5.5 \cdot 10^{15} \mathrm{molec}^{-2}$. For daily averages of tropospheric $\mathrm{NO}_{2}$ columns, a correlation of 0.72 was found for all observations, and 0.79 for cloud free conditions. The measured and modeled tropospheric $\mathrm{NO}_{2}$ columns have an almost identical distribution over the wind direction. A significant difference between model and measurements was found for the average weekly cycle, which shows a much stronger decrease during the weekend for the observations; for the diurnal cycle, the observed range is about twice as large as the modeled range. The results of the comparison demonstrate that averaged over a long time period, the tropospheric $\mathrm{NO}_{2}$ column observations are representative for a large spatial area despite the fact that they were obtained in an urban region. This makes the MAX-DOAS
\end{abstract}

technique especially suitable for validation of satellite observations and air quality models in urban regions.

\section{Introduction}

Tropospheric reactive nitrogen $\left(\mathrm{NO}_{\mathrm{x}}=\mathrm{NO}+\mathrm{NO}_{2}\right)$ has an important role in atmospheric chemistry. It is a key factor in chemical cycles, that also involve tropospheric ozone and the hydroxyl radical $\mathrm{OH}$, the first of which is an air pollutant and a greenhouse gas, and the second of which is the main oxidizing radical of the troposphere, essential in the removal of trace gases, carbon monoxide, methane and volatile organic compounds. In addition, $\mathrm{NO}_{\mathrm{x}}$ has a climate impact through its indirect effect on the radiative forcing via trace gases such as methane, ozone and sulfate (Shindell et al., 2009). In combination with ammonia, $\mathrm{NO}_{\mathrm{x}}$ can form nitric acid, which may lead to a worsening of respiratory diseases, and aggravate heart diseases. Through it's reactions in the atmosphere $\mathrm{NO}_{\mathrm{x}}$ strongly contributes to the formation of photochemical smog and aerosols, which may lead to an increase of respiratory and heart diseases (Brunekreef and Sunyer, 2003). In the atmosphere $\mathrm{NO}_{\mathrm{x}}$ is transformed to nitric acid, which contributes to the acidification of soils and lakes. $\mathrm{NO}_{\mathrm{x}}$ is therefore an essential ingredient in atmospheric chemistry transport models that are used for example to forecast air quality several days ahead. Huijnen et al. (2010) describes a comparison of tropospheric $\mathrm{NO}_{2}$ column forecasts over Europe for 2008-2009 by several regional air quality models and 
by the OMI (Ozone Monitoring Instrument) satellite instrument (Levelt et al., 2006). Although the ensemble of models shows a reasonable agreement with OMI, substantial differences are reported between individual models and OMI, in seasonal and diurnal cycles. The differences are related to the use of different emission databases, transport schemes, chemical mechanisms and meteorological processes in the model, but also to uncertainties in the OMI retrieval. More validation and model process intercomparisons are needed, in order to address the various causes of the observed differences.

While satellite observations have their strength in the spatial coverage, e.g., daily global coverage for OMI, they typically have no more than one overpass per day, for midlatitudes sometimes two within $1.5 \mathrm{~h}$. This makes the current generation of polar orbiting satellite instruments unsuitable for studies of diurnal variations, although a combination of satellites with different overpass times partially solves this problem (Boersma et al., 2009). In addition, the shielding effect of clouds to $\mathrm{NO}_{2}$ in the low troposphere (Boersma et al., 2004), introduces a fair weather bias in satellite observations. The MAX-DOAS (Multi-Axis Differential Optical Absorption Spectroscopy) method (see, e.g., Hoenninger et al., 2004; Wittrock et al., 2004) provides a way to measure tropospheric $\mathrm{NO}_{2}$ columns from the ground. MAX-DOAS observations can be performed under daylight conditions, and below clouds. From the MAX-DOAS perspective clouds also have a shielding effect to $\mathrm{NO}_{2}$ above the cloud; however, this is most often only a small part of the tropospheric $\mathrm{NO}_{2}$ column, because tropospheric $\mathrm{NO}_{2}$ primarily resides in the boundary layer below the cloud (see end of Sect. 2.2.1).

Although within air quality models there is a strong relationship between $\mathrm{NO}_{2}$ concentrations at the surface and tropospheric $\mathrm{NO}_{2}$ columns, a comparison of each of those two quantities with local observations will highlight different aspects of the model. Since real surface concentrations may show strong peaks in the direct vicinity of sources, the spatial representativity of in situ observations is different for urban and for rural sites. For instance, near major roads the $\mathrm{NO}_{\mathrm{x}}$ concentration often increases by 1 order of magnitude compared to the area-mean background. If the spatial representativity of a measurement site is very different from that of the model grid cell, a comparison is difficult. It is therefore concluded in, e.g., Blond et al. (2007) that in urban regions in situ observations cannot be used to validate chemical transport models, or measurement techniques, with a resolution greater than some kilometers.

Tropospheric column measurements have a larger spatial representativity than surface concentrations. The measured concentration at a certain location in a polluted region will be dominated by the nearest source, since these emissions have undergone the least dilution. In terms of concentrations, this dilution takes place in three spatial dimensions. The contribution to the measured concentration of various sources close by and further away will show a strong dependency on the distance to each source. Tropospheric columns on the contrary will not show an equally strong dependence on the distance to sources. Column amounts are generally less reduced due to mixing because they are only affected by horizontal and not by vertical mixing.

In addition, when using only the $30^{\circ}$ and zenith measurements from the MAX-DOAS (Fig. 1), the vertical decrease in sensitivity is relatively low between the surface and the top of the boundary layer; see Sect. 2.2.1. This implies that $\mathrm{NO}_{2}$ well above the surface (often quite well-mixed air) is sampled with almost an equal relative weight as $\mathrm{NO}_{2}$ close to the surface and local sources. Averaging over time (1 h) also reduces the difference in representation between model and observations. This implies that the spatial representativeness of MAX-DOAS tropospheric column observations is, even for an urban site, quite comparable to that of a regional air quality model. Note that a comparison based on tropospheric columns will determine the quality of the model to describe emissions, transport and lifetime of air pollution, which the determine urban background level of $\mathrm{NO}_{2}$ concentrations. The comparison cannot be used to assess the ability of the model to simulate peak concentrations near sources.

In the present work a 14-month data set of MAX-DOAS tropospheric $\mathrm{NO}_{2}$ column observations performed in De Bilt, the Netherlands, is used. This measurement site can certainly not be characterized as rural, with several highways and local roads around it and only four kilometers from the city center of Utrecht (approximately 300000 inhabitants). The data set is compared with Lotos-Euros regional air quality model forecasts (Schaap et al., 2008), run at $7 \times 7 \mathrm{~km}^{2}$ resolution for the Netherlands and surrounding area.

First we describe the spectral analysis of the MAX-DOAS observations, by means of the DOAS method (Platt and Stutz, 2008), where so-called differential slant $\mathrm{NO}_{2}$ columns are derived. Subsequently, it is described how air mass factors are determined and used to convert the differential slant $\mathrm{NO}_{2}$ column measurements to (vertical) tropospheric $\mathrm{NO}_{2}$ columns. Air mass factors are derived both for cloud free and for cloudy conditions. It is shown that calculation of air mass factors under cloudy conditions, especially under partially cloudy conditions, requires detailed knowledge of both the vertical $\mathrm{NO}_{2}$ profile, and the vertical position of the cloud, in two viewing directions. Since this information is not available in full detail at each moment in time for each viewing direction, several assumptions are made, as described in Sect. 2.2.2. Ceilometer observations are used to estimate the cloud bottom height. A relatively high viewing elevation angle is used, $30^{\circ}$, to minimize the sensitivity to aerosols. Furthermore, this choice of elevation does not require detailed knowledge of the exact vertical distribution of $\mathrm{NO}_{2}$.

The comparison of MAX-DOAS observations with the Lotos-Euros air quality model consists of four parts: a selection of individual days is presented to illustrate typical agreements and differences without averaging; a comparison of all tropospheric $\mathrm{NO}_{2}$ columns in the data set, on an hourly 


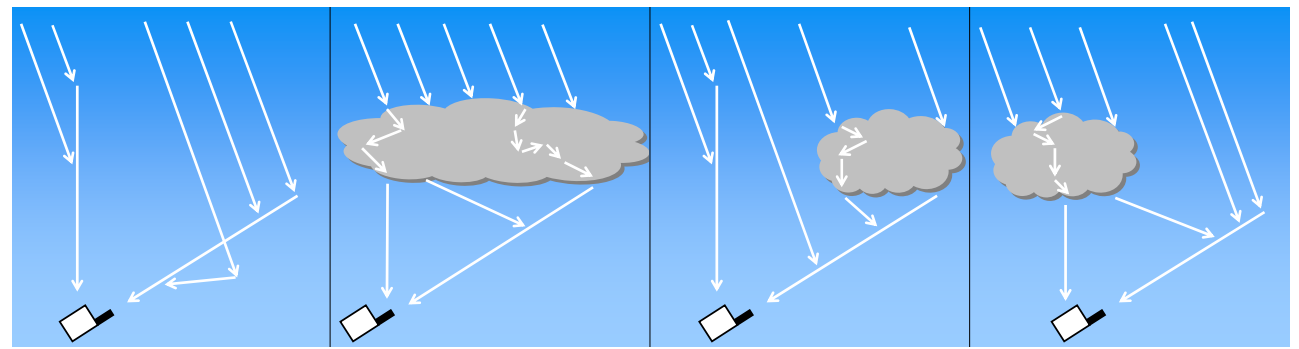

Figure 1. Schematic of MAX-DOAS measurement for four different conditions of cloudiness: cloud free, cloud covered, a cloud at $30^{\circ}$ elevation only, and a cloud only in the zenith direction. The MAX-DOAS differential slant $\mathrm{NO}_{2}$ column measurement is derived from measurements in these two directions, both done within $1 \mathrm{~min}$.

basis, as well as daily averages; a comparison of temporal cycles (season, weekly, diurnal); and a comparison of tropospheric $\mathrm{NO}_{2}$ columns as a function of meteorological parameters: temperature, wind direction, wind speed, and boundary layer height.

\section{MAX-DOAS}

\subsection{Measurements}

In this study a so-called "mini MAX-DOAS" instrument produced by Hoffmann GmbH (Germany) - was used. It is essentially a ground-based spectrometer which can observe UV/Vis spectra (290-433 nm) of scattered sunlight at multiple elevations. Light is collected through a small telescope $\left(f=40 \mathrm{~mm}\right.$, FWHM of field of view $\left.0.45^{\circ}\right)$ and transported through an optical fiber to an Ocean Optics USB2000 crossed Czerny-Turner type spectrometer. Laboratory measurements with a mercury line source have been used to measure the line shape, which has a FWHM (full width at half maximum) of around $0.6 \mathrm{~nm}$ at $408 \mathrm{~nm}$. The instrument was operated by a script which was called from the DOASIS (DOAS Intelligent System)software package (distributed by the Institute of Environmental Physics, University of Heidelberg). This script controls amongst others the integration time and the elevation angle sequence. Spectral measurements $I_{\alpha}(\lambda)$ were recorded at the following elevation angles $\alpha: 0,2,4,8,16,30$ and $90^{\circ}$, but for this study only the last two elevations were used; see Sect. 2.2. For each elevation angle the total integration time was set to $30 \mathrm{~s}$ and therefore 12 or more (depending on the brightness variability of the sky) full elevation scans could be made within $1 \mathrm{~h}$. For more details on the instrument calibration and analysis of the measurements; see Vlemmix et al. (2010).

Observations were performed in De Bilt, the Netherlands $\left(52.101^{\circ} \mathrm{N}, 5.178^{\circ} \mathrm{E}\right.$; see Fig. 4) between November 2007 and April 2009; see also Vlemmix et al. (2010). From May to the first week of September 2008 no measurement could be performed because of instrumental problems. In total, observations were performed on 355 days, of which 289 days had $5 \mathrm{~h}$ of observations or more that passed the quality control (see below).

The MAX-DOAS instrument was located on the roof of the KNMI (Royal Netherlands Meteorological Institute) building. It was aimed towards the northeast, with an azimuth viewing angle of $46^{\circ}$ relative to north, such that a free horizon could be observed and such that the azimuth difference with respect to the azimuth angle of the sun was never less than $45^{\circ}$ during the measurement period.

\subsection{Retrieval}

The DOAS procedure (Platt and Stutz, 2008) was applied to derive information on the $\mathrm{NO}_{2}$ absorption from the spectral observations $I_{\alpha}(\lambda)$. In this method, a separation is made between the broadband part of the absorption cross section $\sigma_{i}(\lambda)$ of the $n$ trace gases absorbing in the spectral window of interest, and the "differential" cross section $\Delta \sigma_{i}(\lambda)$ (obtained after subtracting a low order polynomial fit from $\left.\sigma_{i}(\lambda)\right)$ which has a structure that is characteristic for each trace gas. Because the differential cross sections corresponding to the various trace gases are linearly independent, they can be separated in a fitting procedure. This so called DOAS fit is based on the equation

$\ln \left[\frac{I_{\alpha}(\lambda)}{I_{\mathrm{ref}}(\lambda)}\right]=-\sum_{i=1}^{n} \Delta \sigma_{i}(\lambda) \Delta N_{i, \alpha}^{S}+P(\lambda)$,

where $P(\lambda)$ denotes a low-order polynomial that accounts for the broadband effects. In this study, a third-order polynomial was used. $\Delta N_{i, \alpha}^{S}$ denotes the differential slant column density for elevation $\alpha$ for each of the $n$ trace gases and expresses the difference in trace gas absorption between the light observed at viewing elevation $\alpha$ and the zenith direction. The above equation is numerically solved for $\Delta N_{i, \alpha}^{S}$ and $P(\lambda)$ using a fitting routine minimizing the differences between both sides of the equation.

The MAX-DOAS instrument used in this study has a spectral range from 290 to $433 \mathrm{~nm}$. The spectral window from 415 to $430 \mathrm{~nm}$ was selected for the DOAS fit, because this is the interval within the detector range where the $\mathrm{NO}_{2}$ absorption cross section has its most pronounced differential structures. 
A DOAS fit was made with QDOAS-software (Fayt et al., 2011) using the absorption cross sections of $\mathrm{NO}_{2}(298 \mathrm{~K}$; Vandaele et al., 1998) and $\mathrm{O}_{3}$ (243 K; Bogumil et al., 2003), as well as a ring cross section based on a solar spectrum from Kurucz et al. (1984) in order to take the effect of rotational Raman scattering into account (Chance and Spurr, 1997). A temperature correction was applied after the fitting, based on the temperature dependency of the differential structures in the $\mathrm{NO}_{2}$ cross section, and on the observed temperature at the measurement site (10 min data) from which the average boundary layer temperature is determined assuming a US standard vertical temperature profile shape.

After processing of all available spectra, it was found that the DOAS fits had a mean rms (root mean square) of residual of 0.001 . In order to estimate the detection limit of the measurements the QDOAS analyses of the full data set were used to plot the relative differential slant column error as a function of the retrieved differential slant column (Fig. 2). This figure demonstrates that the detection limit for the differential slant $\mathrm{NO}_{2}$ column (with this particular instrument and for spectra obtained with an integration time of $30 \mathrm{~s}$ ) is

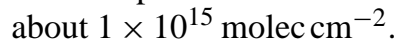

For the present work, MAX-DOAS differential slant $\mathrm{NO}_{2}$ column measurements were averaged over a period of $1 \mathrm{~h}$, starting and ending at the half hours. This was done because the viewing elevation used $\left(30^{\circ}\right)$ tends to show relatively high temporal fluctuations compared to lower elevations: it is less sensitive to $\mathrm{NO}_{2}$ in the boundary layer, and it has a relatively local character (see below), which makes individual $30 \mathrm{~s} \mathrm{ob-}$ servations sensitive to fluctuations in the $\mathrm{NO}_{2}$ field close to the measurement site, whereas the Lotos-Euros model runs on a $7 \times 7 \mathrm{~km}^{2}$ grid. Typically between 12 and 14 differential slant column measurements, each of $30 \mathrm{~s}$, were averaged. If the average relative fitting error within this hour was above $25 \%$, the data was excluded from the comparison (about $15 \%$ of the total number of observations). This procedure for example excludes measurements taken under conditions with fog or snow.

Although the $30^{\circ}$ elevation has a relatively low sensitivity to $\mathrm{NO}_{2}$ in the boundary layer, the primary advantage of this viewing angle is that, in contrast to lower viewing elevations, it has a vertical sensitivity that is quite constant with altitude in the vertical domain where most $\mathrm{NO}_{2}$ is found, i.e., in the boundary layer. In addition, it is also relatively insensitive to aerosols in the boundary layer; see Table 2 and Fig. 1 in Vlemmix et al. (2011).

Lower elevations have vertical sensitivity curves that peak towards the surface, which makes them more sensitive to $\mathrm{NO}_{2}$ in the boundary layer, and which give them a larger horizontal domain of representativity (typically $5 \mathrm{~km}$ for low elevations, depending on aerosol conditions, compared to $1-2 \mathrm{~km}$ for $30^{\circ}$ ). A conversion of differential $\mathrm{NO}_{2}$ slant columns, measured at low elevations, to vertical $\mathrm{NO}_{2}$ columns therefore would require accurate knowledge of the vertical distribution of $\mathrm{NO}_{2}$. It has been shown in, e.g., Vlem-

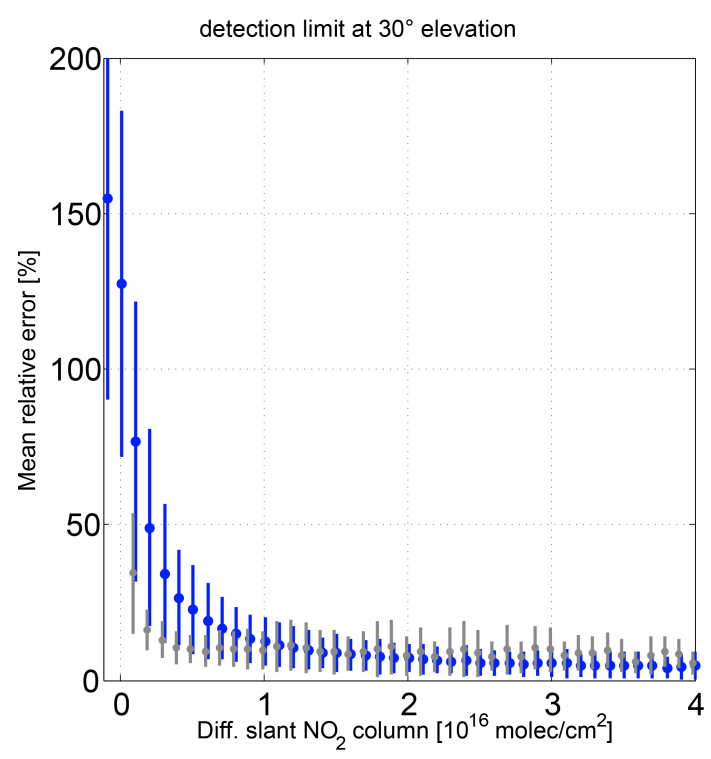

Figure 2. Mean relative error of the fitted differential slant $\mathrm{NO}_{2}$ column as a function of the differential slant $\mathrm{NO}_{2}$ column. Error bars in this figure indicate 2 times the root-mean-square deviation. Blue refers to results obtained from individual spectra (integration time $30 \mathrm{~s}$ ) and gray refers to results obtained after averaging all differential slant column fits (for this elevation) obtained within $1 \mathrm{~h}$. These results only include spectra taken at $30^{\circ}$ elevation (with the zenith spectrum as a reference).

mix et al. (2011) that the potential of the MAX-DOAS technique to derive this vertical distribution is limited, especially above $1 \mathrm{~km}$ altitude. On top of that, such profile retrieval is especially challenging under cloudy conditions, which form the largest part of the data set.

\subsubsection{Sensitivity to clouds}

In this section we will give a qualitative description of the impact of clouds on MAX-DOAS observations. In the next section we describe how we account for clouds in the retrieval.

Figure 3 shows that clouds have a shielding effect for $\mathrm{NO}_{2}$ above the cloud, but only if the cloud is seen in both of the two viewing directions used for the DOAS analysis. In this situation, the cloud acts as a diffuser (see also Wagner et al., 2011), effectively redistributing directional differences in $\mathrm{NO}_{2}$ absorption above the cloud bottom height. The MAX-DOAS measurement is sensitive to the difference in $\mathrm{NO}_{2}$ absorption along the two viewing directions (the zenith direction and the $30^{\circ}$ elevation). This difference essentially originates below the cloud bottom height, since the last scattering altitude will in general be below the cloud (or very low in the cloud), and only after this last scattering moment the angle is determined with which a photon reaches the instrument. The sensitivity to $\mathrm{NO}_{2}$ decreases rapidly to zero above the cloud bottom height. Below the cloud bottom height, the 

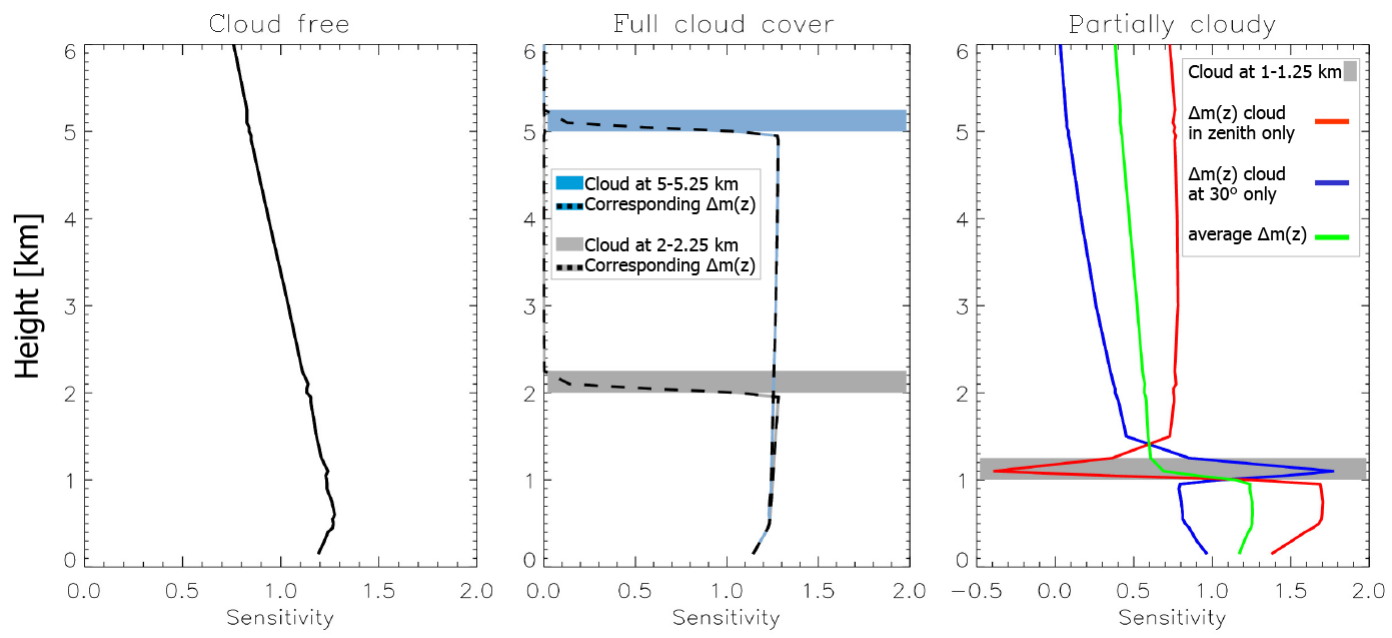

Figure 3. The vertical sensitivity to $\mathrm{NO}_{2}$, or height-dependent differential air mass factors, for cloud free conditions (left panel), a homogeneous cloud cover with a cloud at $2-2.25$ or $5-5.25 \mathrm{~km}$ altitude (middle panel), and partially cloudy conditions with a cloud at $1-1.25 \mathrm{~km}$ altitude (right panel). For partially cloudy conditions, the cloud can be in the zenith (red), or at $30^{\circ}$ elevation (blue). The green line illustrates the time averaged sensitivity when fields of broken clouds pass over the measurement site. Notice the agreement between this line, below the cloud bottom height $(<1 \mathrm{~km})$, and the sensitivity in the same vertical domain for full cloud cover (middle panel).

sensitivity to $\mathrm{NO}_{2}$ is almost constant and independent of the cloud height. The difference between the cloudy and cloud free sensitivity is small below $1 \mathrm{~km}$, but increases above $1 \mathrm{~km}$.

The effect of clouds on the height-dependent sensitivity to $\mathrm{NO}_{2}$ is more complicated when the cloud is seen in only one direction. Since the average photon path length through a horizontal layer of the atmosphere is enhanced within a cloud, the absorption by $\mathrm{NO}_{2}$ at the altitude of the cloud increases. The net effect of this increased absorption is different when the cloud is present only above the zenith or when it is present only in the nonzenith direction. In the first case a reduced or negative sensitivity is seen, depending on the cloud optical thickness, in the second case there is an increase in sensitivity to $\mathrm{NO}_{2}$ at the same height as the cloud. Below the cloud bottom height, the opposite is seen: a cloud only in the zenith leads to an increase in sensitivity from 1.25 to 1.70 compared to a homogeneous cloud cover (or cloud free case), whereas a cloud at $30^{\circ}$ elevation leads to a decrease in sensitivity from 1.25 to 0.80 . Thus, a cloud moving from the $30^{\circ}$ elevation to the zenith can lead to an increase in the measured differential slant column by more than $100 \%$, even when there is no $\mathrm{NO}_{2}$ above the cloud bottom height and when the amount of $\mathrm{NO}_{2}$ below the cloud remains constant. However, on average, situations with a cloud above the zenith will occur as frequently as situations with a cloud at $30^{\circ}$. The time-averaged sensitivity below scattered clouds is the same as the sensitivity below a homogeneous cloud cover; see the green line in Fig. 3. It is therefore concluded that partly cloudy conditions do have a strong effect on individual differential slant column measurements, but the effect averages out when taking an average over many observations (as long as the $\mathrm{NO}_{2}$ is found below the cloud; see the next
Table 1. Selection criteria for air mass factor calculations, based on the cloud conditions.

\begin{tabular}{lll}
\hline Category & cloud cover (octas) & air mass factor \\
\hline Cloud free & $<1$ & cloud free \\
Partially cloudy & $1<\ldots<7$ & cloud covered \\
Cloud covered & $>7$ & cloud covered \\
\hline
\end{tabular}

section): measurements are first averaged over $1 \mathrm{~h}$, and often over many days (Sect. 4.2).

The effect of clouds on the differential slant $\mathrm{NO}_{2}$ column measurements is not only determined by the possible effects that clouds have on the vertical sensitivity to $\mathrm{NO}_{2}$, but also depends on the $\mathrm{NO}_{2}$ profile. $\mathrm{NO}_{2}$ above the cloud bottom height is not detected in the MAX-DOAS observations in cases of homogeneous cloud cover. For partially cloudy conditions, the $\mathrm{NO}_{2}$ above the cloud bottom height is detected, but can only be interpreted if both the $\mathrm{NO}_{2}$ vertical profile and the vertical extent of the cloud is known. Also for cloud free conditions, the sensitivity to $\mathrm{NO}_{2}$ decreases with altitude. It is therefore important to know the height of the cloud bottom for each time of measurement, and additionally which part of the $\mathrm{NO}_{2}$ is located below the cloud. In principle, cloud bottom heights can be derived from the MAX-DOAS observations themselves; see Takashima et al. (2009). However, the accuracy of this (passive remote sensing) method is expected to be generally lower than that of lidar (ceilometer) observations, provided that the lidar observations are performed at the same site as the MAX-DOAS $\left(\mathrm{NO}_{2}\right)$ measurements. For this study it was decided to use observations performed with the LD40 lidar (Vaisala Oyj, 2006; 

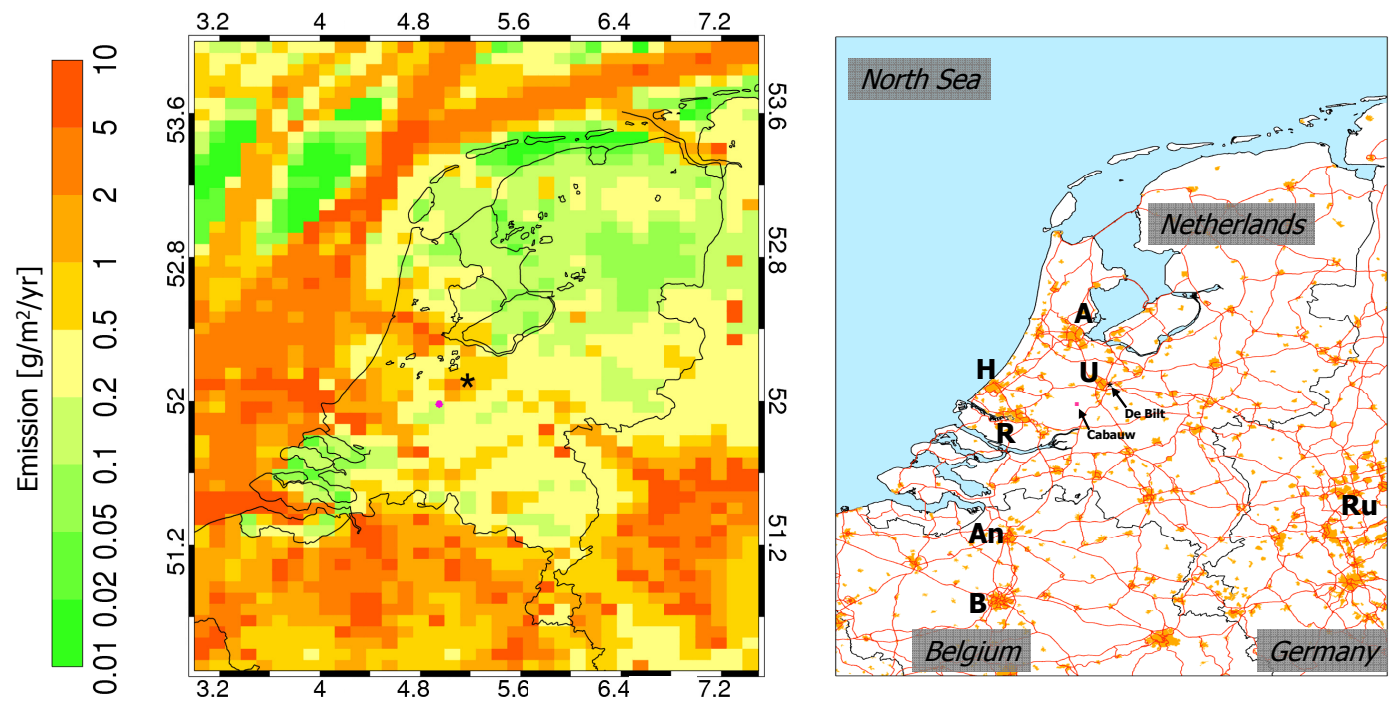

Figure 4. Left: $\mathrm{NO}_{\mathrm{x}}$ emission inventory by $\mathrm{TNO}$ for the Netherlands, the northern, most densely populated part of Belgium, the German Ruhr area, and the North Sea, on a $7 \times 7 \mathrm{~km}^{2}$ grid. The high emissions present in the North Sea are subject to a large uncertainty. The border effect seen between Belgium and the Netherlands is due to the fact that the emissions are based on national inventories, with different sources for each country. The MAX-DOAS instrument was located in De Bilt, indicated with a black asterisk. Cabauw is indicated with a pink circle. Right: a map of the same region, showing highways and large cities: Utrecht (U), Amsterdam (A), The Hague (H), Rotterdam (R), Antwerp (An), Brussels (B) and the Ruhr area (Ru).

Wauben et al., 2006), taken at the same location in De Bilt as the MAX-DOAS measurements (approximately $100 \mathrm{~m}$ horizontal distance). Based on the ceilometer data, a distinction was made between three types of cloudiness; see Table 1 . The average cloud cover, expressed in octas, was determined from the ceilometer time series for each hour over which the MAX-DOAS data were averaged. If this cloud cover was below 1 octa, then the measurement was categorized as cloud free. Mixed cloud conditions were defined as having a cloud cover of between 1 and 7 octas, and cloud covered conditions were defined by an average cloud cover above 7 .

It should be noted that the ceilometer, having a lidar pointing straight up in the sky, does not have the same field of view as the MAX-DOAS instrument. However, the ceilometer is still considered useful for two reasons: firstly because it provides an estimate of cloud bottom height, and secondly because it can make an adequate distinction between the categories (i) cloud free, (ii) partially cloudy, (iii) and cloud covered. It is only under partially cloudy conditions that the exact timing of the presence of clouds may differ for the LD40 and the MAX-DOAS.

In order to have a first-order estimate of the $\mathrm{NO}_{2}$ profile, it was decided not to use the MAX-DOAS measurements themselves (see the discussion above), but rather to use the assumption that all of the tropospheric $\mathrm{NO}_{2}$ is homogeneously distributed in the boundary layer of which the height is taken from ECMWF (European Centre for MediumRange Weather Forecasts) operational weather analysis data. This profile assumption closely resembles the Lotos-Euros description of the $\mathrm{NO}_{2}$ profile. This model uses the assumption that the boundary layer is well mixed and reaches an altitude given by the boundary layer height resulting from the ECMWF analyses. Above the boundary layer the model has two reservoir layers. Those residual layers in general do not contain much $\mathrm{NO}_{2}$ : during the observation period the model on average puts $90 \%$ of the tropospheric $\mathrm{NO}_{2}$ in the boundary layer, and only in $20 \%$ of the cases more than $25 \%$ of the tropospheric $\mathrm{NO}_{2}$ was located above the boundary layer.

Through combination of ceilometer observations of cloud bottom height and the Lotos-Euros $\mathrm{NO}_{2}$ profile description, it was found that averaged over the entire observation period only in $8 \%$ of the cases more than $10 \%$ of the $\mathrm{NO}_{2}$ was found above the cloud bottom height. This low fraction of $\mathrm{NO}_{2}$ above the cloud bottom height is more difficult to detect from the surface, resulting in a potential bias. For this reason we consider for the Lotos-Euros model only the part of the tropospheric $\mathrm{NO}_{2}$ column that is located below the observed cloud bottom height.

\subsubsection{Air mass factors}

Air mass factors were derived for both cloud free and cloudy conditions. For cloudy conditions, a separation can be made between a homogeneous cloud cover and broken cloud conditions (see Fig. 1). In the first case the cloud is seen both at $30^{\circ}$ elevation and in the zenith (reference) direction. In the second case the cloud is seen in only one of the two directions. 
Radiative transfer simulations are performed with the plane parallel model DAK (Doubling Adding KNMI). The DAK model is based on the doubling-adding algorithm for multiple scattering of sunlight in a vertically inhomogeneous atmosphere; see De Haan et al., 1987, Stammes et al., 1989, and Stammes, 2001.

The vertical sensitivity of the MAX-DOAS technique to $\mathrm{NO}_{2}$, more accurately described as the height-dependent differential air mass factor $\Delta m(z)$ (also referred to as boxdifferential air mass factor), is calculated both for cloud free conditions and for conditions including clouds; see Fig. 3. To derive $\Delta m(z)$ from radiative transfer model simulations, first the differential air mass factor of $\mathrm{NO}_{2}$ at height $z$ is calculated. The height-dependent slant column $\mathrm{N}_{\alpha}^{\mathrm{S}}(z)$ is simulated by adding a partial $\mathrm{NO}_{2}$ column, denoted as $\mathrm{N}^{\mathrm{V}}$, to a horizontal layer with height $z$ :

$\mathrm{N}_{\alpha}^{\mathrm{S}}(z)=-\frac{1}{\sigma_{\mathrm{NO}_{2}}} \ln \left(\frac{I_{\alpha}^{\mathrm{NO}_{2}}}{I_{\alpha}^{0}}\right)$,

where $I_{\alpha}^{0}$ is the simulated sky radiance without the $\mathrm{NO}_{2}$ and $I_{\alpha}^{\mathrm{NO}_{2}}$ is the simulated sky radiance with $\mathrm{NO}_{2}(\lambda=427 \mathrm{~nm})$ at a certain altitude $z . \sigma_{\mathrm{NO}_{2}}$ denotes the absorption cross section of $\mathrm{NO}_{2}$. Height-dependent slant columns were calculated for cloud free as well as for cloud covered conditions. Clouds are described as a thick aerosol layer with an optical thickness of 20, a single scattering albedo of 1.0 and an asymmetry parameter of 0.85 .

Because the MAX-DOAS technique typically uses a zenith reference, the vertical sensitivity is determined by the difference in vertical sensitivity for viewing elevation $\alpha$ and the zenith direction. The vertical sensitivity to $\mathrm{NO}_{2}$ is described by the height-dependent differential air mass factor $\Delta m(z)$, which is defined as

$\Delta m_{\alpha}(z)=\frac{\mathrm{N}_{\alpha}(z)-\mathrm{N}^{\mathrm{S}} 90^{\circ}(z)}{\mathrm{N}^{\mathrm{V}}}$.

In the case of partially cloudy conditions (see Figs. 1 and 3) $\Delta m_{\alpha}(z)$ is calculated with a cloud in only one direction: $\mathrm{N}_{\alpha}^{\mathrm{S} \text {, incl.cloud }}(z)$ and $\mathrm{N}_{90^{\circ}}^{\mathrm{S} \text {, excl.cloud }}(z)$, or vice versa. In the following, we will no longer explicitly write the elevation dependence of $\Delta m(z)$ and $\Delta M$, because only one elevation will be used: $\alpha=30^{\circ}$.

The differential air mass factors $\Delta M$ that are needed to convert the measured differential slant columns determined from the DOAS fit (Sect. 2.1), not only depend on the heightdependent differential air mass factors but also on the $\mathrm{NO}_{2}$ profile shape. It is assumed here that $\mathrm{NO}_{2}$ is homogeneously distributed in the boundary layer, and that no $\mathrm{NO}_{2}$ is present above the boundary layer. Lidar observations of $\mathrm{NO}_{2}$ profiles show that this is often the case; see e.g., Volten et al. (2009). The boundary layer height $\left(H_{\mathrm{b}}\right)$ is taken from ECMWF forecasts. It should be noted that this quantity is subject to a substantial uncertainty of up to several hundreds of meters; see e.g., Seidel et al. (2012). The sensitivity of $\Delta M$ to this parameter is however quite weak; see Table 2.

For cloud free situations, the differential air mass factor $\Delta M^{\mathrm{cf}}$ was calculated according to

$\Delta M_{\theta, \phi}^{\mathrm{cf}}=\frac{\int_{z=0}^{z=H_{\mathrm{b}}} n(z) \Delta m_{\theta, \phi}^{\mathrm{cf}}(z) \mathrm{d} z}{\int_{z=0}^{z=H_{b}} n(z) \mathrm{d} z}$,

where $n(z)$ denotes the vertical $\mathrm{NO}_{2}$ concentration profile characterized by homogeneous mixing in the boundary layer, and $\Delta m_{\theta, \phi}^{\mathrm{cf}}(z)$ denotes the height-dependent differential air mass factor for $\mathrm{NO}_{2}$, calculated for solar zenith angle $\theta$ and relative azimuth angle $\phi$, under cloud free conditions.

For cloud covered and mixed cloud situations a slightly different approach was followed. The approach is based on the assumption that the observed $\mathrm{NO}_{2}$ is found below the cloud bottom height, which, as argued in the previous section, is frequently a reasonable assumption. From this assumption it follows that the same height-dependent differential air mass factor can be used for cloud covered and for partially cloudy conditions, because below the cloud bottom height, the time-averaged height-dependent differential air mass factor $\Delta m(z)$ for partially cloudy conditions will be equal to $\Delta m(z)$ for cloud covered conditions. The air mass factor for cloudy conditions $\Delta M^{\mathrm{c}}$ was therefore calculated as

$$
\Delta M_{\theta, \phi}^{\mathrm{c}}=\frac{\int_{z=0}^{z=H_{\mathrm{c}}} n(z) \Delta m_{\theta, \phi}^{\mathrm{c}}(z) \mathrm{d} z}{\int_{z=0}^{z=\mathrm{H}_{\mathrm{c}}} n(z) \mathrm{d} z},
$$

where $H_{\mathrm{c}}$ denotes the cloud bottom height observed by the ceilometer and $\Delta m_{\theta, \phi}^{\mathrm{c}}(z)$ denotes the height-dependent differential air mass factor for $\mathrm{NO}_{2}$, calculated for solar zenith angle $\theta$ and relative azimuth angle $\phi$, under cloud covered conditions. Under these conditions, the dependency on $\theta$ and $\phi$ is almost negligible. In the case of mixed cloud conditions, the minimum cloud bottom height in the $1 \mathrm{~h}$ time interval was used. This procedure was followed instead of using the mean cloud height primarily because of two reasons. First, when the cloud conditions vary between cloudy and cloud free, it is not trivial how to define a mean cloud height. Second, because the minimum cloud bottom height $H_{\mathrm{c}}$ provides more than the mean cloud bottom height, a good estimate of the boundary layer top height $H_{\mathrm{b}}$. Therefore Eq. (5) approximates Eq. (4) better when using the minimum cloud height than when the mean cloud height was used (the mean could be affected by high cirrus and therefore be considerably higher than $H_{\mathrm{b}}$ ).

Table 2 gives an overview of air mass factor-related errors made in the tropospheric $\mathrm{NO}_{2}$ column retrieval when the actual geophysical conditions (aerosol optical thickness, cloud bottom height, aerosol profile height, $\mathrm{NO}_{2}$ profile height) are different from those assumed in the retrieval model. Errors are all below $10 \%$ and mostly below $5 \%$, except for two (similar) extreme cases. In those cases the cloud bottom is 
Table 2. Percentage of errors in the retrieved tropospheric vertical $\mathrm{NO}_{2}$ column, when variables indicated in the upper row are different from the reference value (indicated in boldface). Also shown are the errors made when wrongly assuming a cloud in case of cloud free conditions and vice versa (two bottom rows). Simulations are performed for a solar zenith angle of $60^{\circ}$ and a relative azimuth angle of $180^{\circ}$.

\begin{tabular}{l|rrrr|rrrr|rr|rr|r}
\hline Variable & \multicolumn{9}{|c|}{ aerosol optical thickness } & \multicolumn{3}{c}{ cld. bottom height $(\mathrm{km})$} & \multicolumn{2}{c}{ top aer. layer $(\mathrm{km})$} & \multicolumn{2}{c}{ top $\mathrm{NO}_{2}$ layer $(\mathrm{km})$} \\
range & 0.1 & $\mathbf{0 . 2}$ & 0.4 & 0.8 & 0.5 & 1.0 & 1.5 & $\mathbf{5 . 0}$ & 0.5 & $\mathbf{1 . 0}$ & 0.5 & $\mathbf{1 . 0}$ \\
\hline Cloud free & 5.0 & 0.0 & -3.0 & -1.6 & $\mathrm{n} / \mathrm{a}$ & $\mathrm{n} / \mathrm{a}$ & $\mathrm{n} / \mathrm{a}$ & $\mathrm{n} / \mathrm{a}$ & -1.6 & 0.0 & 1.5 \\
Cloudy & 1.0 & 0.0 & -1.1 & 2.0 & 81.4 & -0.8 & -0.2 & 0.0 & -2.9 & 0.0 & 3.5 & 0.0 \\
Cld. fr., cloudy assumed & -1.7 & -2.7 & -3.8 & -0.8 & 76.6 & -3.4 & -2.9 & -2.7 & -5.5 & -2.7 & 0.8 & -2.0 \\
Cloudy, cld. fr. assumed & 7.9 & 2.7 & -0.4 & 1.07 & 2.4 & 2.4 & 2.4 & 2.7 & 1.1 & 2.7 & 4.3 & 2.7 \\
\hline
\end{tabular}

in reality at $0.5 \mathrm{~km}$, whereas it is assumed to be at $5 \mathrm{~km}$. Under these conditions the cloud shows considerable overlap with the $\mathrm{NO}_{2}$ profile (assumed to be between the surface and $1 \mathrm{~km}$ ) and considerably reduces the sensitivity to most of the $\mathrm{NO}_{2}$ within the cloud. This effect is taken into account by comparing the observations only with the part of the model $\mathrm{NO}_{2}$ profile that is below the measured cloud bottom height (as described in Sect. 2.2.1).

\section{Lotos-Euros}

The chemistry-transport model Lotos-Euros (Schaap et al., 2008) is the national air quality model for the Netherlands. Since 2009 the model is used operationally to provide daily air pollution forecasts. It has recently been used for a dynamic traffic control experiment (de Ruyter de Wildt et al., 2011) and it provides daily forecasts and analysis of air quality in Europe in the context of the European MACC project (Monitoring Atmospheric Composition and Climate; http://www.gmes-atmosphere.eu/). The model has been used for the assessment of particulate matter PM $_{10}$ (Denby et al., 2008), and secondary inorganic components (Barbu et al., 2009; Schaap et al., 2004). Lotos-Euros has taken part in international model comparisons addressing ozone (van Loon et al., 2007; Kukkonen et al., 2012).

The intercomparisons with the MAX-DOAS instrument are based on the latest version of the model, Lotos-Euros v1.7. The model is driven by meteorological fields (forecasts) from the ECMWF. The emission inventory used (Fig. 4) is developed by TNO for the MACC project, and covers Europe with a resolution of $7 \times 7 \mathrm{~km}^{2}$ (Kuenen et al., 2011). Model simulations were performed for the full period for which MAX-DOAS observations are available. These consist of nested runs. First, a lower-resolution run is performed on the European domain $\left(15^{\circ} \mathrm{W}-35^{\circ} \mathrm{E}, 35^{\circ} \mathrm{N}-70^{\circ} \mathrm{N}\right)$ with a resolution of $0.5^{\circ}$ by $0.25^{\circ}$. Secondly, a high resolution nested run $\left(2^{\circ} \mathrm{W}-14^{\circ} \mathrm{E}, 46^{\circ} \mathrm{N}-56^{\circ} \mathrm{N}\right)$ is performed for the Netherlands and surroundings at a resolution of about $7 \mathrm{~km}$ $\left(0.125^{\circ}\right.$ longitude by $0.0625^{\circ}$ latitude), equivalent to the resolution of the emission inventory. The model uses a bulk boundary layer scheme with four vertical layers: a surface layer of $25 \mathrm{~m}$, a single boundary layer with a thickness de- pending on the time of day (layer 2). The layer 2 height is obtained by interpolating in time the boundary layer height field provided by ECMWF, available every $3 \mathrm{~h}$. Layers 3 and 4 are reservoir layers, and the top of the model is $3.5 \mathrm{~km}$.

Since the MAX-DOAS observations are only sensitive to $\mathrm{NO}_{2}$ below the cloud, the Lotos-Euros profile was integrated up to the observed cloud height and only this partial column was included in the comparison. As noted in Sect. 2.2, on average only a small fraction of the $\mathrm{NO}_{2}$ was found above the cloud height.

\section{Comparison}

In this section we will describe the comparison of the MAX-DOAS tropospheric $\mathrm{NO}_{2}$ column observations with the Lotos-Euros model. First a selection of individual days will be shown. Several moments of significant agreement or difference will be discussed in detail. Then the data set is analyzed in more detail with a focus on temporal variations (diurnal, weekly, seasonal) and meteorological effects.

\subsection{Examples of individual comparisons}

The comparison between MAX-DOAS and Lotos-Euros for a selection of individual days (3-18 April 2009) is shown in Fig. 5. This series of 16 days consists of 5 clear sky and 11 partially cloudy days. In general a quite good agreement can be seen. On cloud free days the MAX-DOAS retrieval is less variable than on some of the days which are partially cloudy. This may be due to successive under- and overestimations of the air mass factor under partially cloudy conditions, as argued in Sect. 2.2.1.

Several moments of striking agreement and disagreement may to some extent be explained by the similarities and differences between the model and the observations in the meteorological conditions, and in the weekly cycle. For example, the 4, 5, 11 and 12 April 2009 were weekend days, and 13 April was a public holiday in the Netherlands. In the model the decrease in emissions on such days is most probably underestimated; see below and Fig. 9. This provides a possible explanation for the high tropospheric $\mathrm{NO}_{2}$ columns of the Lotos-Euros model relative to the observations. 


\section{April 2009}
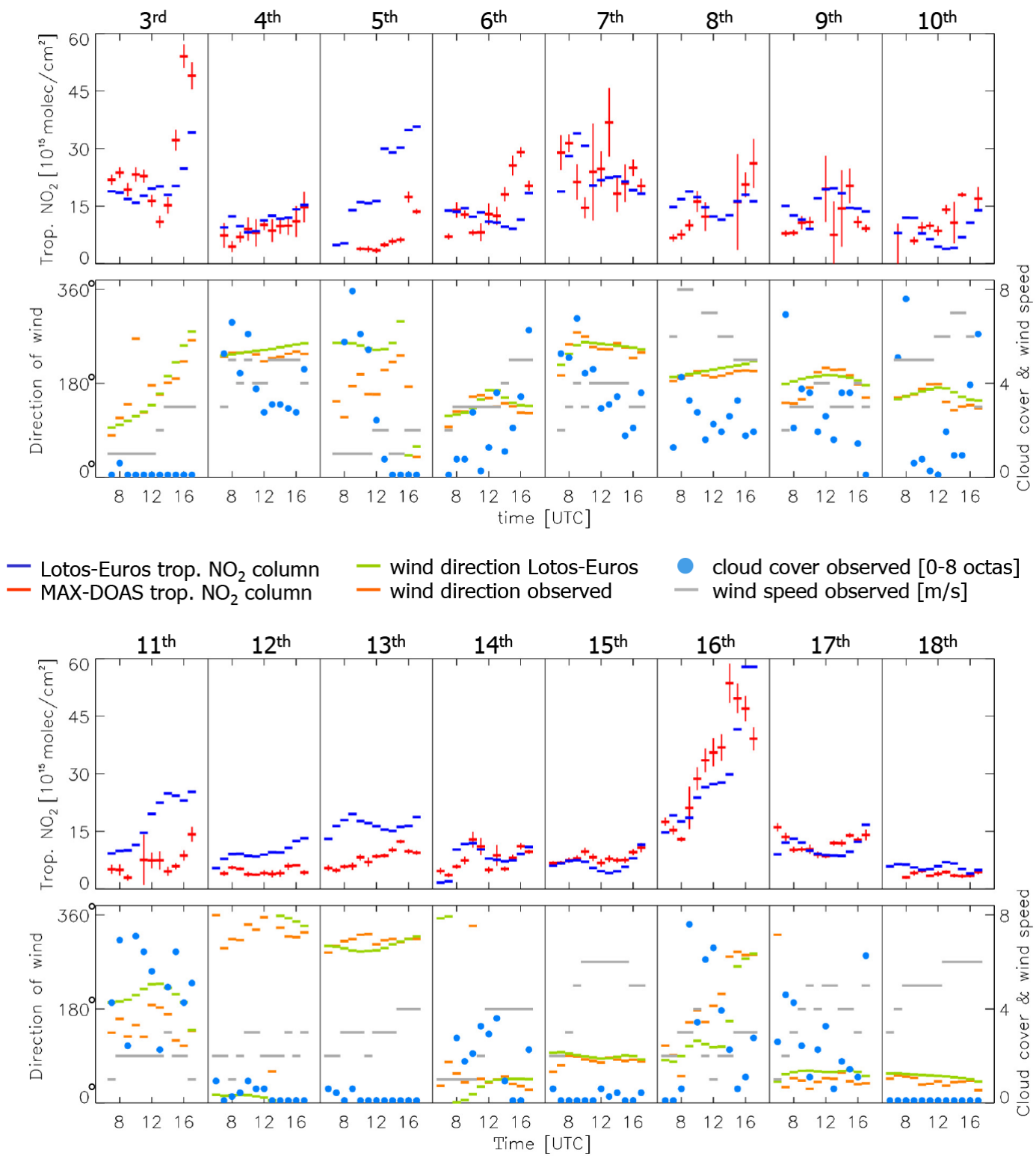

Figure 5. Comparison between MAX-DOAS and Lotos-Euros tropospheric $\mathrm{NO}_{2}$ columns and simultaneous meteorological conditions for 16 days in April 2009. The uncertainty in the MAX-DOAS retrieval is determined from the rms of the individual observations that are averaged over $1 \mathrm{~h}$.

Furthermore, it is shown in Sect. 4.4 that the tropospheric $\mathrm{NO}_{2}$ column on average shows a dependence on the wind direction. On 16 April, the change of the wind from the east, through the south, to the west, may be causing the strong rise in both the observed and modeled tropospheric $\mathrm{NO}_{2}$ column. This effect is also visible on 3 April. Although it is shown in Fig. 5 that the observed wind direction at the measurement site and the ECMWF wind direction used in the Lotos-Euros model generally show a good agreement, quite substantial differences are seen on 5 and 11 April. As in this situation the modeled wind comes from a more polluted sector than the measured wind (according to Fig. 11), it is well possible that this increases the difference in the tropospheric $\mathrm{NO}_{2} \mathrm{col}-$ umn, in addition to the weekend effect. A similar effect can be seen on 16 April: the change of the model wind shows a time lag with respect to the observed wind, which turns to the polluted sector 1 or $2 \mathrm{~h}$ earlier. Finally, the dependence of the tropospheric $\mathrm{NO}_{2}$ column on the wind direction is seen from 7 to 10 April: here the direction of the wind changes 
slowly in the course of these 4 days, and the tropospheric $\mathrm{NO}_{2}$ column decreases accordingly.

April 5 is, according to the Lotos-Euros model, the day with the highest daily averaged tropospheric $\mathrm{NO}_{2}$ column in the 14-month data set. The measurements, on the contrary, show low values. On this day several causes of difference between the model and the observations come together: (i) it is a Sunday, thus emissions may be overestimated by the model; (ii) the wind in the model comes from a more polluted sector than the observed wind; and (iii) the wind speed on this day was very low, about $1 \mathrm{~m} \mathrm{~s}^{-1}$; see Fig. 5. In Sect. 4.4 it is shown that on average there is an increase in the tropospheric $\mathrm{NO}_{2}$ column with decreasing wind speed. Wind speeds were low in both the model and in the measurements, but the combination of low wind speeds with (i) and (ii) may have lead to this relatively extreme model value. Because of this particular combination of effects, this day is considered to be not representative and therefore it was excluded from the comparison of daily averages, described in Sect. 4.2.

\subsection{Quantitative analysis}

The comparison of hourly data is shown in Fig. 6 and Table 3. It shows that in general the distribution of tropospheric $\mathrm{NO}_{2}$ columns for the model and the measurements are in good agreement (left panel). The average difference is very small, $<1 \%$ (right panel) of the average tropospheric $\mathrm{NO}_{2}$ column $\left(14.5 \cdot 10^{15} \mathrm{molec} \mathrm{cm}^{-2}\right)$. However, the measurements show somewhat more values below $10 \cdot 10^{15}$ molec $\mathrm{cm}^{-2}$, as well as more extremes above $30 \cdot 10^{15}$, which leads to a positive intercept of the linear regression $\left(3.58 \cdot 10^{15} \mathrm{molec} \mathrm{cm}^{-2}\right)$, and a slope of 0.76 ; see Table 3 . This slope below 1 may solely be due to a difference in spatial representativity between model and observations; see the discussion below (after the next paragraph). The differences between model and observations can quite accurately be described by a Gaussian distribution with a standard deviation $(\sigma)$ of $5.5 \cdot 10^{15} \mathrm{molec} \mathrm{cm}^{-2}$ (all data included), which indicates that the differences behave as a random variable.

The impact of processing different subsets of the hourly data, based on the cloud conditions, does not have a strong effect on these results (slope, intercept); see Fig. 6 (right panel) and Table 3. However, if no correction for the observed cloud bottom height would have been performed on the modeled tropospheric $\mathrm{NO}_{2}$ columns, Lotos-Euros tropospheric $\mathrm{NO}_{2}$ columns would on average have been $1.65 \cdot 10^{15}$ molec $\mathrm{cm}^{-2}$ higher than MAX-DOAS tropospheric $\mathrm{NO}_{2}$ columns, which demonstrates that the cloud correction cannot be omitted. Table 3 also shows that the standard deviation of differences between model and observations is significantly lower for cloud free conditions, $\sigma=4.6 \cdot 10^{15}$ molec $\mathrm{cm}^{-2}$, than for cloud covered conditions: $\sigma=6.1 \cdot 10^{15}$ molec $\mathrm{cm}^{-2}$. However, the correlation for cloud covered conditions is somewhat better than for sunny conditions.
Figure 7 and Table 4 show a comparison between MAXDOAS and Lotos-Euros based on daily averages. Only days with more than $5 \mathrm{~h}$ of data were used. The correlation, slope and intercept all show an improvement with respect to the comparison based on hourly averages. As noted above, this partly illustrates the fact that the spatial representativeness is more equivalent between model and observations for daily than for hourly averaged data. Excluding the Saturdays and Sundays reduces the intercept, but increases the average difference somewhat. The cloud free days show the best results, with a correlation of 0.79 , a linear regression with a slope of 0.89 and an intercept of less than $1 \cdot 10^{15} \mathrm{molec}^{-2}$. The reduction of scatter, indicated by the improved correlation relative to the $1 \mathrm{~h}$ data, also leads to a reduction of differences: absolute differences above $20 \%$ are seen for only $20 \%$ of the cases (all daily averages). For sunny weather situations only $14 \%$ of the cases have a difference above $20 \%$.

\subsection{Diurnal, weekly and monthly cycles}

Figure 8 shows monthly averages of tropospheric $\mathrm{NO}_{2}$ columns. In general, the same pattern is followed by the model and the observations. The observations show a slightly stronger seasonal variation: the observations in the winter months have slightly higher values than the model, and the spring and autumn months are somewhat lower. This may indicate a temperature-related effect, which is discussed in Sect. 4.4. Figure 8 also shows the number of observation hours for each month. Some months have fewer or no observations because of instrumental problems in that period (November and December 2007, from May to midSeptember 2008). The reduction of daylight hours in the winter is another reason for fewer observations in those months. The model data was used only for hours when good quality observations were performed. Summer months were not included in the comparison. Huijnen et al. (2010) reports an underestimation for an ensemble of air quality models in the summer months, based on a comparison with observations from the OMI satellite instrument.

The weekly cycle is shown in Fig. 9. Here it can be seen that the observations show a stronger weekly cycle than the model. Whereas in the model the variations around the mean of $14.5 \cdot 10^{15}$ molec $\mathrm{cm}^{-2}$ are no larger than $1.5 \cdot 10^{15}$ molec $\mathrm{cm}^{-2}$, the measurements show a peak of $17 \cdot 10^{15} \mathrm{molec}^{-2}$ on Thursday, and a minimum of $9 \cdot 10^{15}$ molec cm $^{-2}$ on Sunday. For some part, the less pronounced weekly cycle found for the model can be related to a moderate weekly cycle of traffic (both for diesel and gasoline engines). A similar weekly pattern as for the observations is found for cities in Europe using GOME (Global Ozone Monitoring Experiment) satellite observations (Beirle et al., 2003), and with OMI observations (J.P. Veefkind, S. Beirle, personal communication, 2011). It may be concluded that the weekend emissions are likely overestimated by the 
Table 3. Comparison of $1 \mathrm{~h}$ averages of tropospheric $\mathrm{NO}_{2}$ columns from MAX-DOAS (MD) and Lotos-Euros (LE). $\sigma_{\text {diff }}$ denotes the standard deviation of the Gaussian fit to the differences between MD and LE; see Fig. 6. Columns 3, 4, 5, 8 and 9 are in $10^{15} \mathrm{molec}^{-2}$.

\begin{tabular}{lrrrrrrrr}
\hline Selection & $\mathrm{N}$ & avg. MD & avg. LE & avg. diff. & corr. & slope & intercept & $\sigma_{\text {diff }}$ \\
\hline All data & 2106 & 14.53 & 14.60 & -0.07 & 0.60 & 0.76 & 3.58 & 5.5 \\
Cloud covered & 190 & 13.29 & 13.74 & -0.45 & 0.64 & 0.73 & 4.00 & 6.1 \\
Partially cloudy & 1435 & 15.04 & 14.98 & 0.05 & 0.58 & 0.76 & 3.54 & 5.6 \\
Sunny & 481 & 13.50 & 13.79 & -0.29 & 0.62 & 0.74 & 3.75 & 4.6 \\
\hline
\end{tabular}

Table 4. Comparison of daily averages of tropospheric $\mathrm{NO}_{2}$ columns from MD and LE. Only days with at least $5 \mathrm{~h}$ of data were used.

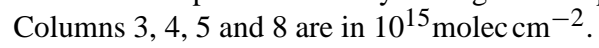

\begin{tabular}{lrrrrrrr}
\hline Selection & N & avg. MD & avg. LE & avg. diff. & corr. & slope & intercept \\
\hline All data & 289 & 14.52 & 14.44 & -0.08 & 0.72 & 0.86 & 1.94 \\
Excl. weekend & 217 & 15.59 & 14.73 & -0.86 & 0.74 & 0.86 & 1.36 \\
Sunny & 34 & 14.44 & 13.93 & -0.51 & 0.79 & 0.89 & 0.97 \\
\hline
\end{tabular}

model, which is compensated by an underestimation during the week; see also Table 4.

The average diurnal cycle of the tropospheric $\mathrm{NO}_{2}$ columns is shown in Fig. 10. For this figure only data from the months September, October (2008) and March and April (2008 and 2009) were used, because these months have more or less the same number of daylight hours, in contrast to the winter months. Both the model and the observations show an increase during the day, but the increase is much smaller for the model, about $28 \%$, than for the observations, which almost show a doubling. On Sundays the increase is much smaller, and its shape is more in agreement with the model. The winter months (November-February, not shown) also show a stronger diurnal increase for the observations, but this effect can only be observed for a smaller portion of the day, because of the limited daylight period. Various effects may cause this difference in the diurnal cycle. It may be related to the temporal variations of the emissions in the model (especially the 2 rush-hour peaks), being possibly smaller than those observed in De Bilt from Monday to Friday. The model may also not respond as quickly to the peak emissions in the rush hour as the observations do. Also, a different ratio between passenger cars and trucks around the measurement site, as compared to the model, may explain a difference in diurnal cycle, since emissions of $\mathrm{NO}_{2}$ due to passenger cars (mainly gasoline) show a stronger peak around the 2 rush hours than emissions by trucks (mainly diesel).

\subsection{Dependence on meteorological conditions}

The dependence of tropospheric $\mathrm{NO}_{2}$ columns from MAXDOAS and Lotos-Euros on various meteorological parameters was investigated: cloudiness, wind speed, wind direction, relative humidity, precipitation (all based on observations performed at the same site as the MAX-DOAS mea- surements), temperature and boundary layer height (from ECMWF data).

No significant differences or patterns were seen for relative humidity and precipitation. For cloud cover $>5$ octa an underestimation by MAX-DOAS was found of about 5$10 \%$, which may be related to the shielding effect of clouds to $\mathrm{NO}_{2}$ above the cloud bottom height in combination with an error in the estimated vertical $\mathrm{NO}_{2}$ profile in the model. For partially cloudy conditions between 2 and 5 octas, an overestimation by the same amount was found. This could be due to the fact that for the Lotos-Euros model only the partial column up to the cloud height is considered, even for partially cloudy conditions, whereas the green line in Fig. 3 (right panel) indicates that the MAX-DOAS sensitivity above this height is halved, but not zero.

As noted above, the seasonal dependence of the differences between model and observations (Fig. 8) might be temperature related because, for instance, temperature and season are strongly related. A linear regression applied to the MAX-DOAS observations plotted as a function of temperature resulted in a slope of $-0.20 \pm 0.01 \cdot 10^{15}$ molec cm $^{-2} \mathrm{~K}^{-1}$ (only observations between 10:00 and 13:00 UTC (universal time coordinated) were considered). The observed decrease with increasing temperature is expected, because $\mathrm{NO}_{\mathrm{x}}$ lifetimes are generally shorter for higher temperatures and fewer hours of daylight; see e.g., Schaub et al. (2007). For LotosEuros almost no temperature dependence was found: slope $0.00 \pm 0.01 \cdot 10^{15}$ molec $\mathrm{cm}^{-2} \mathrm{~K}^{-1}$. However, when the LotosEuros data set is not restricted to days with MAX-DOAS observations but a full year is considered including a summer period (October 2008-September 2009), then a temperature dependence is found: $-0.27 \pm 0.01 \cdot 10^{15}$ molec $\mathrm{cm}^{-2} \mathrm{~K}^{-1}$. It is therefore not likely that the apparent absence of a temperature dependence for the model indicates a systematic model error. It is more probably due to the large variability in tropospheric $\mathrm{NO}_{2}$ columns (Fig. 6) and a relatively narrow tem- 

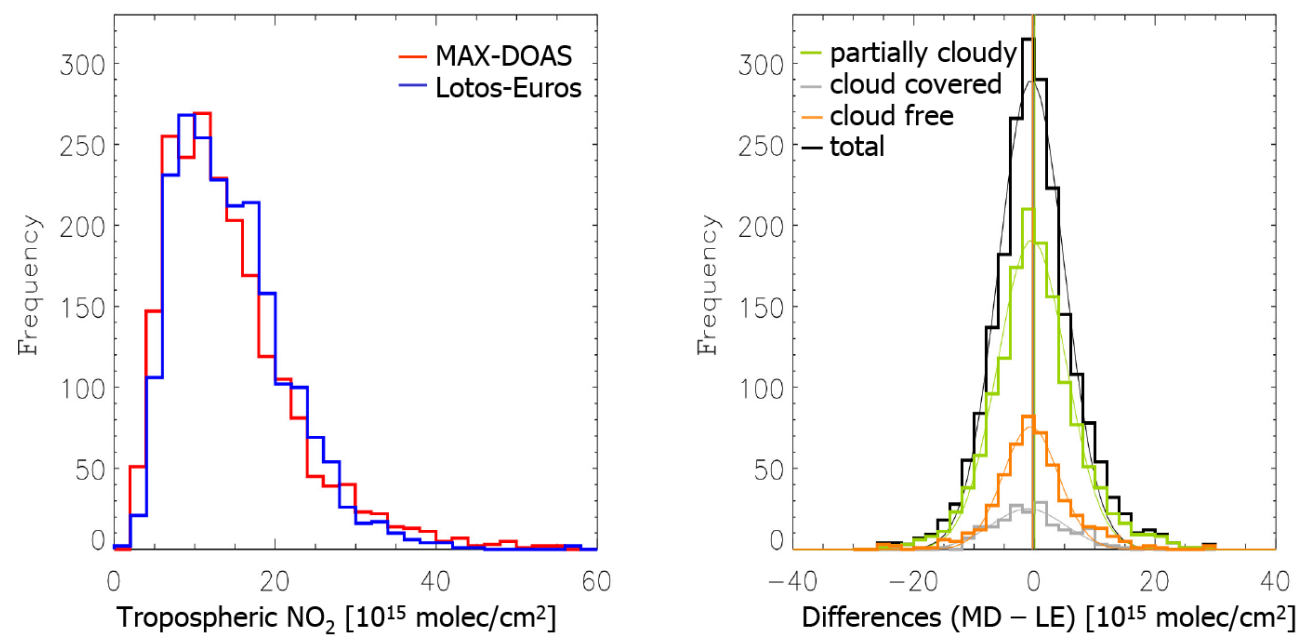

Figure 6. Histogram of $1 \mathrm{~h}$ averaged tropospheric $\mathrm{NO}_{2}$ columns observed with MAX-DOAS and of Lotos-Euros (left panel), and a histogram of differences (right panel), subdivided according to cloudiness, as explained in Table 1. The vertical lines indicate the average differences of each subset. Also shown are Gaussian fits to the histogram of differences. See also Table 3.

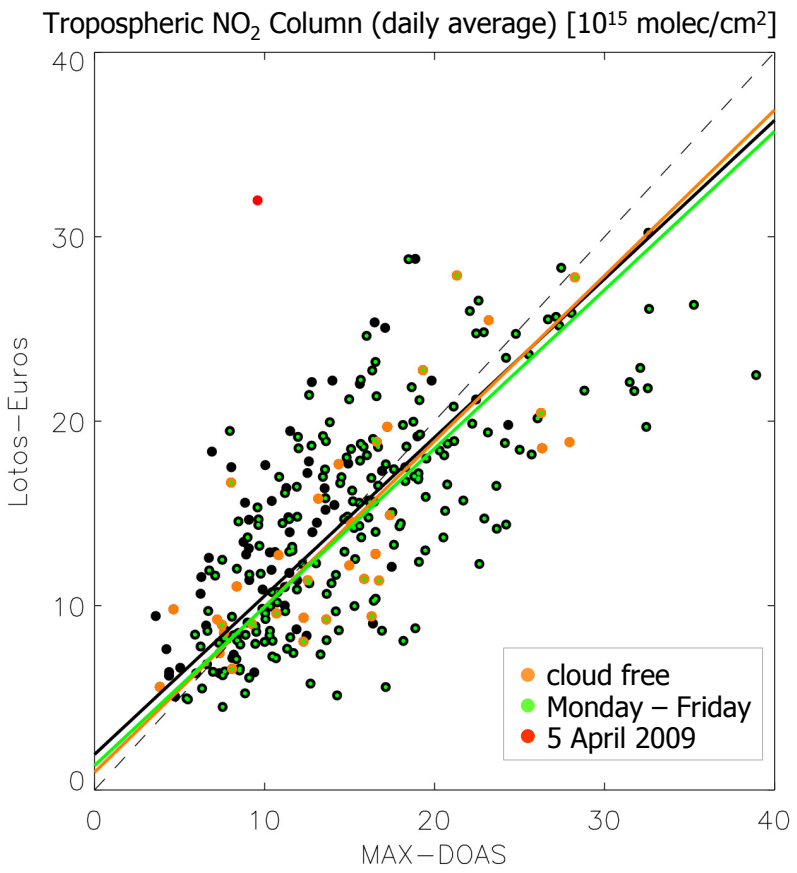

Figure 7. Scatter plot of tropospheric $\mathrm{NO}_{2}$ columns averaged over each day with at least $5 \mathrm{~h}$ of observations (all points). Quantitative results are shown in Table 4. The 5 April 2009 is considered an outlier, as discussed in Sect. 4.1.

perature range for the selected data record, caused by the absence of measurements in the summer months (the temperature distribution for the selected data has a mean of $6.4^{\circ} \mathrm{C}$ and a standard deviation of $4.5^{\circ} \mathrm{C}$ ). Both effects complicate the determination of the temperature dependence with a linear regression.
Since $\mathrm{NO}_{\mathrm{x}}$ emission sources are not equally distributed around the measurement site (see Fig. 4), it is to be expected that the average tropospheric $\mathrm{NO}_{2}$ column will show a dependency on the direction of the wind. This is illustrated in Fig. 11. A remarkable agreement is found between the observations and the model. It shows that the high-resolution emission database $\left(7 \times 7 \mathrm{~km}^{2}\right)$ used in Lotos-Euros gives an accurate representation of $\mathrm{NO}_{\mathrm{x}}$ emission sources close to, and further away from De Bilt, and that the transport is well described. The cleanest air comes from the northeast, i.e., from parts of the Netherlands and Germany which are less densely populated.

As the city of Utrecht (about 300000 inhabitants) is located to the west of De Bilt, and because there are several highways close to De Bilt (mainly in the west and south), it may be questioned if the observed $\mathrm{NO}_{2}$ comes from relatively local sources or from further away, such as the Rotterdam region at approximately $50 \mathrm{~km}$ to the west-southwest, and the Belgian Antwerp-Brussels region more to the south at approximately $100-150 \mathrm{~km}$ (see Fig. 4). This question can partially be answered making use of the model alone, which was also run for the location Cabauw $\left(51.97^{\circ} \mathrm{N}, 4.93^{\circ} \mathrm{E}\right)$ which lies on the other side of Utrecht as seen from De Bilt. Cabauw is a site with fewer local sources in the direct vicinity and, from that perspective, a more rural site. No measurements are available for this site for the same period as for De Bilt. In 2005 and 2006 the DANDELIONS (Dutch Aerosol and Nitrogen Dioxide Experiments for vaLIdation of OMI and SCIAMACHY) campaigns (Brinksma et al., 2008; Volten et al., 2009) were held here, and in 2009 the CINDI (Cabauw Intercomparison campaign for Nitrogen Dioxide measuring Instruments) campaign (Piters et al., 2012). During both campaigns there were indications at Cabauw of aged air coming from, e.g., the Ruhr area. Also air coming from 


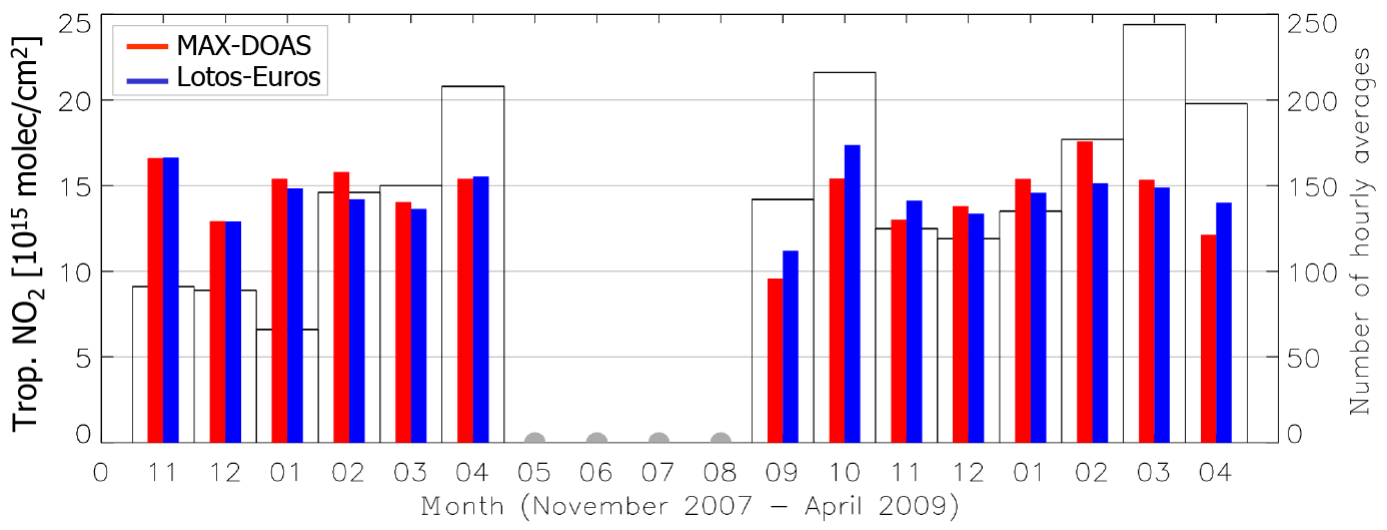

Figure 8. Average tropospheric $\mathrm{NO}_{2}$ columns for each month in the data set. No measurements were performed from May to 10 September 2008. In black, the number of hourly averages for that month is shown, which is lower in the wintertime because of the shorter daylight period. Days with instrumental problems have also reduced the number of observations for some months.

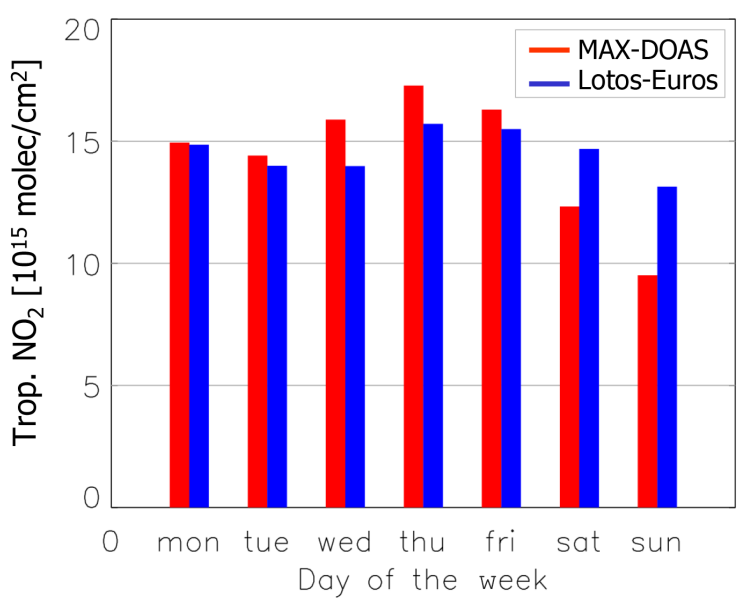

Figure 9. Average tropospheric $\mathrm{NO}_{2}$ column for each day of the week.

Belgium is expected to have a considerable impact on the $\mathrm{NO}_{2}$ levels at De Bilt.

Figure 13 demonstrates that there is considerable agreement between the wind direction dependence of the tropospheric $\mathrm{NO}_{2}$ column for Cabauw and De Bilt. The western and southern sectors are almost equal, which is surprising because the city of Cabauw is located to the southwest of De Bilt, and the relatively large city of Utrecht is located in between. Apparently, the loss in tropospheric $\mathrm{NO}_{2}$ (it has a lifetime of typically a few hours) moving from the direction of the Rotterdam source region over Cabauw (arrow [2]) towards De Bilt (arrow [B]) is compensated by the $\mathrm{NO}_{2}$ added by the Utrecht area. In the opposite direction, air moving from the relatively clean northeastern part of the Netherlands contains a limited amount of $\mathrm{NO}_{2}$ when it arrives at De Bilt (arrow [A]) but when it arrives at Cabauw a significant increase is observed (arrow [1]), which must be due to the Utrecht region. Note in addition that the fraction of the

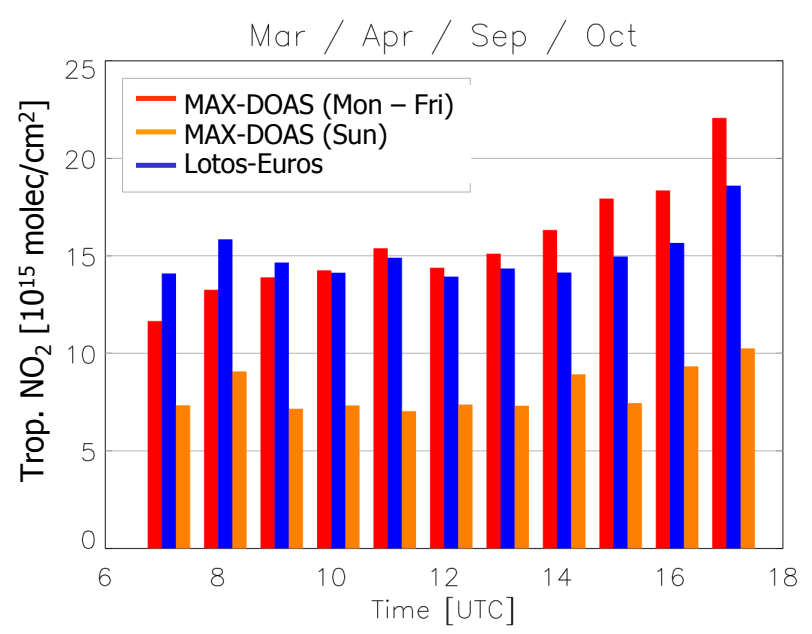

Figure 10. Average tropospheric $\mathrm{NO}_{2}$ column for each hour of the day on weekdays and Sundays, based on the months March, April, September and October in the data set (some months occurred twice; see Fig. 8). These months were grouped because they have approximately the same daylight period. Winter months show a similar behavior (higher MAX-DOAS values in the afternoon). Summer months were not present in the data set. Sundays were only shown for the observations for reasons of clarity: the weekend effect (Fig. 9) would complicate the picture.

Utrecht region that is covered by the southwestern sector as seen from the Bilt is relatively small (because it lies almost against Utrecht), whereas seen from Cabauw, a larger part of the Utrecht area is covered by the northeastern sector.

The sector with the lowest average tropospheric $\mathrm{NO}_{2}$ column for Cabauw is the northwest: $8 \cdot 10^{15} \mathrm{molec} \mathrm{cm}^{-2}$. From this direction, air comes in from the North Sea and on its way to Cabauw moves over what is known as the Green Heart of the Netherlands (arrow [3]), a region dominated by agriculture, located between the four largest cities of the Netherlands; see Fig. 12. The same sector for De Bilt (arrow [C]) 


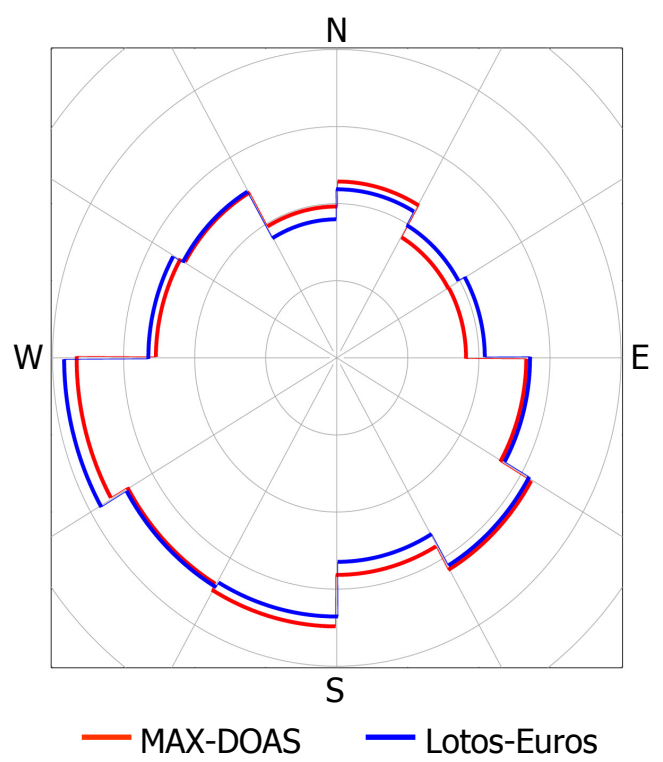

Figure 11. Average of modeled and observed tropospheric $\mathrm{NO}_{2}$ column for De Bilt, for 12 sectors of wind direction. The radius of the inner circle is $5 \cdot 10^{15}$ molec $\mathrm{cm}^{-2}$.

represents air that also came in from the North Sea, most likely with the same $\mathrm{NO}_{2}$ concentrations before reaching the coast, but that passed over the Amsterdam area before reaching De Bilt with an average value of $13 \cdot 10^{15}$ molec $\mathrm{cm}^{-2}$. The difference of $5 \cdot 10^{15}$ molec $\mathrm{cm}^{-2}$ gives an indication of the effect relative to the background of a city like Amsterdam at a distance of $30 \mathrm{~km}$. A similar estimate can be made by considering the northerly winds (not indicated in the map, or in Fig. 13). From this direction the pollution of Amsterdam is blown to Cabauw, whereas from De Bilt towards the north of De Bilt fewer sources are found (Fig. 4).

It may be concluded that the air observed in De Bilt and in Cabauw has for a large part sources far away, such as Amsterdam, the Rotterdam region, Belgium (see the southern sector) and even the German Ruhr region (the southeastern sector). The spatial representativity of the long-term averaged observations is therefore large, even though it is close to sources. This would most probably be quite different for in situ observations of $\mathrm{NO}_{2}$ concentrations at the surface. Also the relatively large agreement of the wind-direction dependence between the (semi) urban De Bilt and rural Cabauw sites indicates that, for tropospheric column observations, the distinction between rural and urban sites is not so important (for a model or satellite versus MAX-DOAS comparison) as in the case of in situ observations (Blond et al., 2007). This view is supported by the results reported in Leigh et al. (2007), where a comparison of tropospheric $\mathrm{NO}_{2}$ columns and in situ observations performed in Leicester (UK) shows for some wind directions a difference by a factor of 2 .

A second, different type of wind effect can also be seen for the observations from De Bilt as well as for the model:

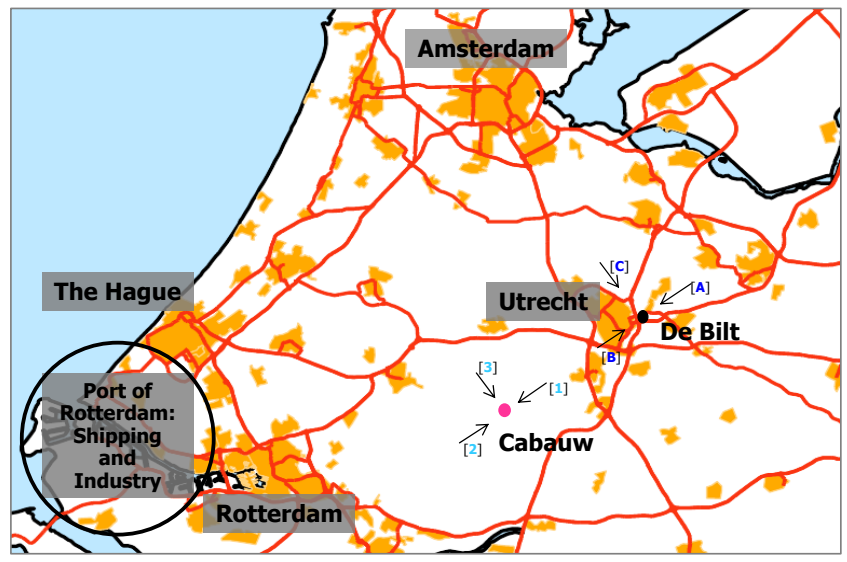

Figure 12. Map of the Randstad region in the Netherlands. Cabauw and De Bilt are $22 \mathrm{~km}$ apart, and have the city of Utrecht in between. The arrows indicate wind directions discussed in the Sect. 4.4, and correspond to the arrows shown in Fig. 13.

tropospheric $\mathrm{NO}_{2}$ columns show an increase with decreasing wind speeds; see Fig. 14. The tropospheric $\mathrm{NO}_{2}$ column in the absence of wind is about $50 \%$ higher than the overall average of $14.5 \cdot 10^{15}$ molec $\mathrm{cm}^{-2}$. The effect is most pronounced for wind speeds below $2 \mathrm{~m} \mathrm{~s}^{-1}$, but also applies to higher wind speeds. A possible explanation for this effect is that with higher wind speeds the $\mathrm{NO}_{2}$ emitted in a certain time period is distributed over a larger volume of air than with lower wind speeds. This reduces the observed tropospheric column downwind of the source region.

For the more rural Cabauw area, with fewer emission sources in the direct vicinity, the wind speed effect is weaker according to the model simulations, where especially for low wind speeds no increase is observed: for wind speeds $<4 \mathrm{~m} \mathrm{~s}^{-1}$ the average tropospheric $\mathrm{NO}_{2}$ column is about $17 \cdot 10^{15}$ molec $\mathrm{cm}^{-2}$, above $4 \mathrm{~m} \mathrm{~s}^{-1}$ the value declines to $11.5 \cdot 10^{15}$ molec $\mathrm{cm}^{-2}$ at $12 \mathrm{~m} \mathrm{~s}^{-1}$.

In Fig. 15 the comparison between Lotos-Euros and MAX-DOAS is shown as a function of boundary layer height. In general, a decrease of tropospheric $\mathrm{NO}_{2}$ columns is seen with increasing boundary layer height, both by the model and the observations. Boundary layers generally increase in the course of the day, due to thermal convection. Low boundary layers therefore more frequently occur in the early morning, and high boundary layers in the early afternoon. In order to exclude interference with the diurnal variation which is different for the model than for the observations (Fig. 10), the comparison was only applied to observations and model output between 10:00 UTC (11:00 LT) and 14:00 UTC (15:00 LT). The decrease of tropospheric $\mathrm{NO}_{2}$ columns with increasing boundary layer height is also observed for the same full year of model simulations that was discussed earlier in this section in relation to the temperature effect (thus including a summer period). This demonstrates the consistency of the boundary layer height effect, also be- 


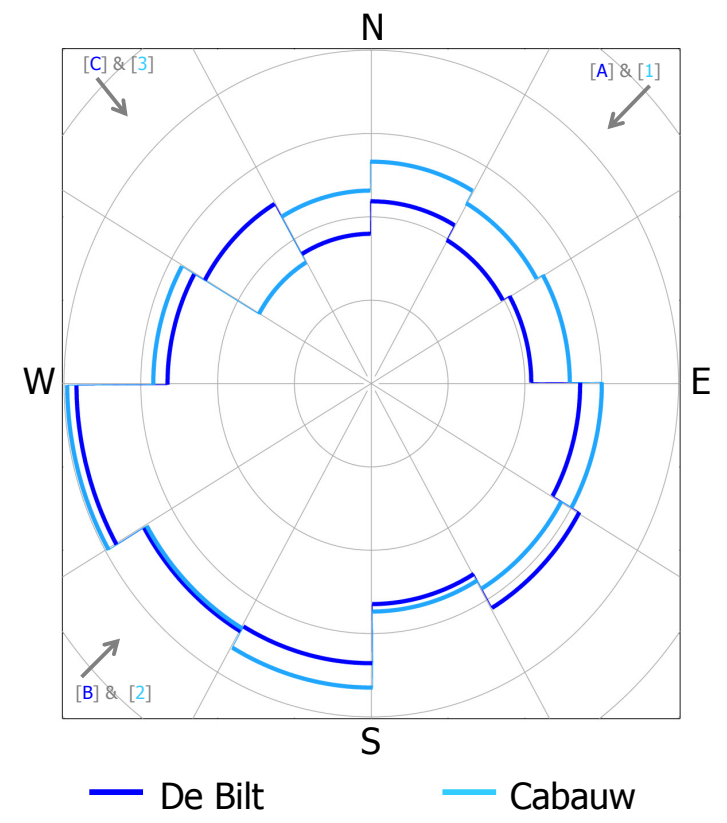

Figure 13. Tropospheric $\mathrm{NO}_{2}$ columns from Lotos-Euros, averaged for 12 sectors of wind direction, for the locations De Bilt and Cabauw. The radius of the inner circle is $5 \cdot 10^{15}$ molec $\mathrm{cm}^{-2}$. The arrows correspond to wind directions shown in Fig. 12.

cause no correction based on cloud bottom height was applied in this model simulation, which might be thought to interfere. Figure 15 also shows a (small) decrease for very low boundary layers $(<200 \mathrm{~m})$, but this effect is seen only for the lowest bin, and therefore for a limited amount of observations which may not be representative, considering the large variability in tropospheric $\mathrm{NO}_{2}$ columns (see e.g., Figs. 6 and 5). Since a temperature effect is found for the observations, but not for the model (see the discussion above), it is considered unlikely that the decrease of tropospheric $\mathrm{NO}_{2}$ columns with increasing boundary layer height is solely due to the relation between boundary layer height and temperature. Other seasonal effects, such as variations in daylight, may also play a role.

\section{Conclusions}

A data set of MAX-DOAS tropospheric $\mathrm{NO}_{2}$ column observations has been compared with the Lotos-Euros regional air quality model. The size of the data set (355 days spread over 14 months, 2106 hourly averages) enables statistically significant conclusions and allows us to study the seasonal, weekly and diurnal variability and dependence on meteorological variables. The data set does not include the summer period due to instrumental problems in those months.

The MAX-DOAS retrieval is based on a viewing elevation of $30^{\circ}$ to have a vertical sensitivity to $\mathrm{NO}_{2}$ that is relatively constant with altitude. This significantly reduces a possible

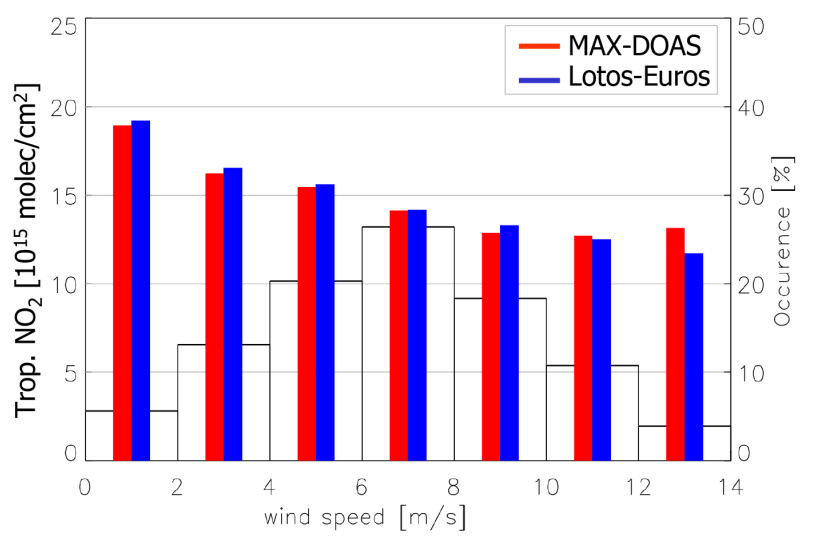

Figure 14. Average tropospheric $\mathrm{NO}_{2}$ column as a function of wind speed. Values above $12 \mathrm{~m} \mathrm{~s}^{-1}$ are not shown because of the low number of data for this domain.

systematic bias due to the mostly unknown vertical distribution of $\mathrm{NO}_{2}$. A LD40 ceilometer located at the same site as the MAX-DOAS instrument was used to determine the cloud height and classify cloud cover. A distinction was made between clear sky conditions, partially cloudy, and cloud covered conditions.

It was shown that the vertical sensitivity to $\mathrm{NO}_{2}$ below a cloud was almost equal to the sensitivity in the absence of clouds. Even for partly cloudy conditions, the time-averaged vertical sensitivity has the same value. Accurate retrieval of $\mathrm{NO}_{2}$ above the cloud bottom height is problematic. However, based on cloud bottom height observations (LD40 ceilometer) and Lotos-Euros modeled $\mathrm{NO}_{2}$ profiles, it was shown that, averaged over the whole observation period, only in $8 \%$ of the time more than $10 \%$ of the $\mathrm{NO}_{2}$ was found above the cloud bottom height. It is therefore assumed that all $\mathrm{NO}_{2}$ measured by the MAX-DOAS is located below the cloud bottom. Measurements under cloudy conditions are compared with Lotos-Euros tropospheric columns that are integrated up to the measured cloud bottom height.

The overall agreement between the observations and the model is good: both have an average tropospheric $\mathrm{NO}_{2}$ column of about $14.5 \cdot 10^{15}$ molec $\mathrm{cm}^{-2}$, and an average difference is found of $-0.07 \cdot 10^{15} \mathrm{molec} \mathrm{cm}^{-2}(0.5 \%)$. On an hourly basis differences can be large but they closely resemble a Gaussian distribution $\left(\sigma=5.5 \cdot 10^{15} \mathrm{molec} \mathrm{cm}^{-2}\right)$, which indicates that the differences behave as a random variable. The diurnal evolution of tropospheric $\mathrm{NO}_{2}$ columns on specific days only occasionally shows a good agreement, although an exception is formed by periods of clear sky days with winds from the relatively clean northeastern part of the Netherlands. The MAX-DOAS observations show more extreme values $<10 \cdot 10^{15}$ and $>30 \cdot 10^{15}$ molec $\mathrm{cm}^{-2}$. Possible causes of differences are the difference in spatial representativity, random fluctuations of actual emissions, systematic differences in temporal cycles (see below), changed emissions on public holidays, and differences in wind direc- 


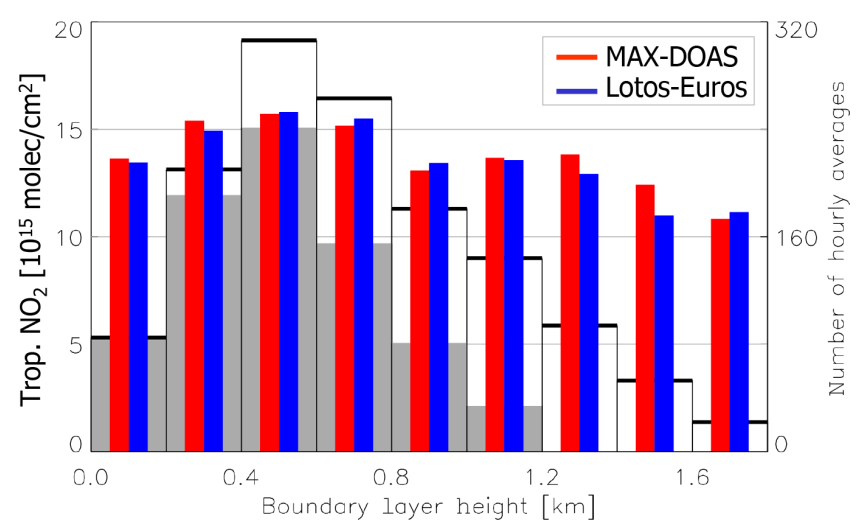

Figure 15. Average tropospheric $\mathrm{NO}_{2}$ column as a function of boundary layer height, averaged over all observations between 10:00 and 14:00 UTC. The histogram in the background gives the number of elements for each bin; in gray, the histogram of winter months (November, December, January, February) is shown. The white part of each bin gives the contribution of the other months: September, October, March, April. Boundary layers lower than $200 \mathrm{~m}$ were almost solely observed in the winter.

tion between the ECMWF model and actual observations at the measurement site. Clouds may have a strong momentary effect on the observations, especially under partially cloudy conditions, leading to larger differences compared to clear sky observations $\left(\sigma_{\text {cloud }}=6.1 \cdot 10^{15}\right.$ and $\sigma_{\text {cloudfree }}=4.6$. $10^{15}$ molec $\mathrm{cm}^{-2}$ ). In our analysis clouds do not introduce a systematic bias because the Lotos-Euros tropospheric $\mathrm{NO}_{2}$ column is integrated only from the surface up to the measured cloud bottom height. Without this correction (i.e. integration of entire vertical profile) Lotos-Euros tropospheric columns would on average be $1.65 \cdot 10^{15}$ molec $\mathrm{cm}^{-2}(11 \%)$ higher than MAX-DOAS columns.

For daily averaged tropospheric $\mathrm{NO}_{2}$ columns a correlation of 0.72 is found and a linear regression shows that Lotos-Euros overestimates relative to the MAX-DOAS for low tropospheric $\mathrm{NO}_{2}$ columns and underestimates for higher columns: the slope of the linear regression is 0.86 and the intercept is $1.94 \cdot 10^{15}$ molec $\mathrm{cm}^{-2}$. If only clear sky days are considered, the correlation increases to 0.79 , and also the slope and intercept improve to 0.89 and 0.97 . $10^{15}$ molec $\mathrm{cm}^{-2}$ respectively.

The MAX-DOAS observations on average show quite pronounced weekly and diurnal cycles, whereas Lotos-Euros in both cases shows only a weak effect. For the weekly cycle, this can partly be explained by a low weekly cycle in the modeled emissions. The more constant diurnal cycle for the model may be due to the fact that the model does not respond as quickly on the peak emissions in the rush hour as the observations do. Also, a different ratio between passenger cars (mainly gasoline) and trucks (diesel) around the measurement site, as compared to the ratio in the model, may explain a different diurnal cycle.
The difference between model and observations appears to have a seasonal variation: the model is higher than the observations in spring and fall and lower in winter. This apparent periodic behavior might be related to temperature (the model shows no temperature correlations $\left(0.00 \pm 0.01 \cdot 10^{15}\right.$ molec $\mathrm{cm}^{-2} \mathrm{~K}^{-1}$ ), whereas the observations show a temperature dependency of $-0.20 \pm 0.01 \cdot 10^{15}$ molec $\mathrm{cm}^{-2} \mathrm{~K}^{-1}$ ), as well as to seasonal fluctuations in the daylight period leading to increased photochemical conversion of $\mathrm{NO}_{2}$. It was found that the small dependence on temperature for the model is not systematic: if summer months are also included (which could only be done for the model), leading to a larger contribution of higher temperatures, then a temperature dependency is found; i.e., $-0.27 \pm 0.01 \cdot 10^{15}$ molec $\mathrm{cm}^{-2} \mathrm{~K}^{-1}$.

The tropospheric $\mathrm{NO}_{2}$ column averaged over the wind directions shows a good agreement between observations and model, indicating that the spatial distribution of sources around the observation site and transport are well captured in the Lotos-Euros model. The tropospheric $\mathrm{NO}_{2}$ columns averaged per sector of wind direction show a remarkable agreement between the measurement site De Bilt (urban) and the rural site Cabauw, for which only model results were available. Both the model and the observations show a quite strong decrease with increasing wind speeds, which is related to local sources around De Bilt. The wind speed effect is weaker for the model simulations at Cabauw, having fewer sources in the direct vicinity.

Finally, the model and observations showed agreement in their average dependence on boundary layer height. A decrease in tropospheric $\mathrm{NO}_{2}$ columns is seen towards higher boundary layers. Since boundary layer heights have a seasonal variation, this effect could not clearly be separated from other seasonal variations affecting tropospheric $\mathrm{NO}_{2}$ abundances; i.e., seasonal variations such as daylight and temperature, two factors also leading to lower tropospheric $\mathrm{NO}_{2}$ columns in summer.

The results of the comparison demonstrate that the tropospheric $\mathrm{NO}_{2}$ column observations, when averaged over a long time period, are representative for a large spatial area despite the fact that they were obtained in an urban region. This makes the MAX-DOAS technique, more than in situ techniques, especially suitable for validation of satellite observations and air quality models in urban regions.

Acknowledgements. The authors greatly acknowledge two anonymous reviewers and the editor for their contribution to this manuscript.

We would like to thank M. Van Roozendael and C. Fayt from the Belgian Institute for Space and Aeronomy (IASB/BIRA) for kindly providing the QDOAS software that was used for the DOAS analysis.

Furthermore, we would like to thank S. Kraus and T. Lehmann of the Institute for Environmental Physics at the University of Heidelberg for providing the DOASIS software package. 
We thank R. Sluiter and R. Leander from KNMI for their contributions to this paper.

This work has been financed by User Support Program Space Research via the project Atmospheric chemistry instrumentation to strengthen satellite validation of CESAR (EO-091).

Edited by: M. Van Roozendael

\section{References}

Barbu, A., Segers, A., Schaap, M., Heemink, A., and Builtjes, P.: A multi-component data assimilation experiment directed to sulphur dioxide and sulphate over europe, Atmos. Environ., 43, 1622-1631, doi:10.1016/j.atmosenv.2008.12.005, 2009.

Beirle, S., Platt, U., Wenig, M., and Wagner, T.: Weekly cycle of $\mathrm{NO}_{2}$ by GOME measurements: a signature of anthropogenic sources, Atmos. Chem. Phys., 3, 2225-2232, doi:10.5194/acp3-2225-2003, 2003.

Blond, N., Boersma, K. F., Eskes, van der A, R. J., Van Roozendael, M., De Smedt, I., Bergametti, G., and Vautard, R.: Intercomparison of SCIAMACHY nitrogen dioxide observations, in situ measurements and air quality modeling results over Western Europe, J. Geophys. Res., 112, D10311, doi:10.1029/2006JD007277, 2007.

Boersma, K. F., Eskes, H. J., and Brinksma, E. J.: Error analysis for tropospheric $\mathrm{NO}_{2}$ retrieval from space, J. Geophys. Res., 109, D04311, doi:10.1029/2003JD003962, 2004.

Boersma, K. F., Jacob, D. J., Trainic, M., Rudich, Y., DeSmedt, I., Dirksen, R., and Eskes, H. J.: Validation of urban $\mathrm{NO}_{2}$ concentrations and their diurnal and seasonal variations observed from the SCIAMACHY and OMI sensors using in situ surface measurements in Israeli cities, Atmos. Chem. Phys., 9, 3867-3879, doi:10.5194/acp-9-3867-2009, 2009.

Bogumil, K., Orphal, J., Homann, T., Voigt, S., Spietz, P., Fleischmann, O. C., Vogel, A., Hartmann, M., Kromminga, H., Bovensmann, H., Frerick, J., and Burrows, J. P.: Measurements of Molecular Absorption Spectra with the SCIAMACHY PreFlight Model: Instrument Characterization and Reference Data for Atmospheric Remote-Sensing in the 230-2380 nm Region, J. Photochem. Photobiol. A., 157, 167-184, 2003.

Brinksma, E. J., Pinardi, G., Volten, H., Braak, R., Richter, A., Schoenhardt, A., Van Roozendael, M., Fayt, C., Hermans, C., Dirksen, R. J., Vlemmix, T., Berkhout, A. J. C., Swart, D. P. J., Oetjes, H., Wittrock, F., Wagner, T., Ibrahim, O., de Leeuw, G., Moerman, M., Curier, R. L., Celarier, E. A., Cede, A., Knap, W. H., Veefkind, J. P., Eskes, H. J., Allaart, M., Rothe, R., Piters, A. J. M., and Levelt, P. F.: The 2005 and 2006 DANDELIONS $\mathrm{NO}_{2}$ and aerosol intercomparison campaigns, J. Geophys. Res., 113, D16S46, doi:10.1029/2007JD008988, 2008.

Brunekreef, B. and Sunyer, J.: Asthma, rhinitis and air pollution: is traffic to blame?, Eur. Respir. J., 21, 913-915, 2003.

Chance, K. V. and Spurr, R. J. D.: Ring effect studies: Rayleigh scattering, including molecular parameters for rotational Raman scattering, and the Fraunhofer spectrum, Appl. Opt.,36, 52245230, 1997.

De Haan, J. F., Bosma, P. B., and Hovenier, J. W.: The adding method for multiple scattering calculations of polarized light, Astron. Astrophys., 183, 371-393, 1987. de Ruyter de Wildt, M., Eskes, H., Manders, A., Sauter, F., Schaap, M., Swart, D., and van Velthoven, P.: Six-day PM $_{10}$ air quality forecasts for The Netherlands with the chemistry transport model Lotos-Euros, Atmos. Environ., 45, 5586-5594, 2011.

Denby, B., Schaap, M., Segers, A., Builtjes, P., and Horálek, J.: Comparison of two data assimilation methods for assessing $\mathrm{PM}_{10}$ exceedances on the european scale, Atmos. Environ., 42, 7122-7134, 2008 .

Fayt, C., De Smedt, I., Letocart, V., Merlaud, A., Pinardi, G., and Van Roozendael, M.: QDOAS Software user manual, http: //uv-vis.aeronomie.be/software/QDOAS/index.php (last access: August 2011), 2011.

Hönninger, G., von Friedeburg, C., and Platt, U.: Multi axis differential optical absorption spectroscopy (MAX-DOAS), Atmos. Chem. Phys., 4, 231-254, doi:10.5194/acp-4-231-2004, 2004.

Huijnen, V., Eskes, H. J., Poupkou, A., Elbern, H., Boersma, K. F., Foret, G., Sofiev, M., Valdebenito, A., Flemming, J., Stein, O., Gross, A., Robertson, L., D’Isidoro, M., Kioutsioukis, I., Friese, E., Amstrup, B., Bergstrom, R., Strunk, A., Vira, J., Zyryanov, D., Maurizi, A., Melas, D., Peuch, V.-H., and Zerefos, C.: Comparison of $\mathrm{OMI} \mathrm{NO}_{2}$ tropospheric columns with an ensemble of global and European regional air quality models, Atmos. Chem. Phys., 10, 3273-3296, doi:10.5194/acp-10-3273-2010, 2010.

Kuenen, J., Denier van der Gon, H., Visschedijk, A., van der Brugh, H., and Gijlswijk, R.: MACC European emission inventory for the years 2003-2007, TNO report no. TNO-060-UT-201100588, http://atmosphere.copernicus.eu/documents/deliverables/ d-emis/TNO\%20report_UT-00588_MACC_emission2003_ 2007.pdf (last access: December 2014), 2011.

Kukkonen, J., Olsson, T., Schultz, D. M., Baklanov, A., Klein, T., Miranda, A. I., Monteiro, A., Hirtl, M., Tarvainen, V., Boy, M., Peuch, V.-H., Poupkou, A., Kioutsioukis, I., Finardi, S., Sofiev, M., Sokhi, R., Lehtinen, K. E. J., Karatzas, K., San José, R., Astitha, M., Kallos, G., Schaap, M., Reimer, E., Jakobs, H., and Eben, K.: A review of operational, regional-scale, chemical weather forecasting models in Europe, Atmos. Chem. Phys., 12, 1-87, doi:10.5194/acp-12-1-2012, 2012.

Kurucz, R. L., Furenlid, I., and Testerman, L.: Solar Flux Atlas from 296 to $1300 \mathrm{~nm}$, Technical Report, National Solar Observatory, Sunspot, New Mexico, 240 pp., 1984.

Leigh, R. J., Corlett, G. K., Frieß, U., and Monks, P. S.: Spatially resolved measurements of nitrogen dioxide in an urban environment using concurrent multi-axis differential optical absorption spectroscopy, Atmos. Chem. Phys., 7, 4751-4762, doi:10.5194/acp-7-4751-2007, 2007.

Levelt, P. F., van den Oord, G. H. J., Dobber, M. R., Mälkki, A., Visser, H., de Vries, J., Stammes, P., Lundell, J., and Saari, H.: The Ozone Monitoring Instrument, IEEE Trans. Geo. Rem. Sens., (Special Issue on the EOS-Aura mission), 44, 1199-1208, 2006.

Piters, A. J. M., Boersma, K. F., Kroon, M., Hains, J. C., Van Roozendael, M., Wittrock, F., Abuhassan, N., Adams, C., Akrami, M., Allaart, M. A. F., Apituley, A., Beirle, S., Bergwerff, J. B., Berkhout, A. J. C., Brunner, D., Cede, A., Chong, J., Clémer, K., Fayt, C., Frieß, U., Gast, L. F. L., Gil-Ojeda, M., Goutail, F., Graves, R., Griesfeller, A., Großmann, K., Hemerijckx, G., Hendrick, F., Henzing, B., Herman, J., Hermans, C., Hoexum, M., van der Hoff, G. R., Irie, H., Johnston, P. V., Kanaya, Y., Kim, Y. J., Klein Baltink, H., Kreher, K., de Leeuw, 
G., Leigh, R., Merlaud, A., Moerman, M. M., Monks, P. S., Mount, G. H., Navarro-Comas, M., Oetjen, H., Pazmino, A., Perez-Camacho, M., Peters, E., du Piesanie, A., Pinardi, G., Puentedura, O., Richter, A., Roscoe, H. K., Schönhardt, A., Schwarzenbach, B., Shaiganfar, R., Sluis, W., Spinei, E., Stolk, A. P., Strong, K., Swart, D. P. J., Takashima, H., Vlemmix, T., Vrekoussis, M., Wagner, T., Whyte, C., Wilson, K. M., Yela, M., Yilmaz, S., Zieger, P., and Zhou, Y.: The Cabauw Intercomparison campaign for Nitrogen Dioxide measuring Instruments (CINDI): design, execution, and early results, Atmos. Meas. Tech., 5, 457-485, doi:10.5194/amt-5-457-2012, 2012.

Platt, U. and Stutz, J.: Differential Optical Absorption Spectroscopy, Springer-Verlag Berlin Heidelberg, 135-158, 2008.

Schaap, M., van Loon, M., ten Brink, H. M., Dentener, F. J., and Builtjes, P. J. H.: Secondary inorganic aerosol simulations for Europe with special attention to nitrate, Atmos. Chem. Phys., 4, 857-874, doi:10.5194/acp-4-857-2004, 2004.

Schaap, M., Timmermans, R. M. A., Roemer, M., Boersen, G. A. C., Builtjes, P. J. H., Sauter, F. J., Velders, G. J. M., and Beck, J. P.: The lotos- euros model: Description, validation and latest developments, Int. J. Environ. Pollut., 32, 270-290, 2008.

Schaub, D., Brunner, D., Boersma, K. F., Keller, J., Folini, D., Buchmann, B., Berresheim, H., and Staehelin, J.: SCIAMACHY tropospheric $\mathrm{NO}_{2}$ over Switzerland: estimates of $\mathrm{NO}_{\mathrm{X}}$ lifetimes and impact of the complex Alpine topography on the retrieval, Atmos. Chem. Phys., 7, 5971-5987, doi:10.5194/acp-7-5971-2007, 2007.

Seidel, D. J., Zhang, Y., Beljaars, A., Golaz, J. C., Jacobson, A. R., and Medeiros, B.: Climatology of the planetary boundary layer over the continental United States and Europe, J. Geophys. Res., 117, D17106,doi:10.1029/2012JD018143, 2012.

Shindell, D. T., Faluvegi, G., Dorothy, M. K., Schmidt, G. A., Unger, N., and Bauer, S. E.: Improved Attribution of Climate Forcing to Emissions, Science, 326, 716-718, doi:10.1126/science.1174760, 2009.

Stammes, P.: Spectral radiance modeling in the UV-visible range, in: IRS2000: Current problems in atmospheric radiation, edited by: Smith, W. L. and Timofeyev, Y. M., Deepak Publ., A., Hampton (VA), 1, 385-388, 2001.

Stammes, P., de Haan, J. F., and Hovenier, J. W.: The polarized internal radiation field of a planetary atmosphere, Astron. Astrophys., 225, 239-259, 1989.

Takashima, H., Irie, H., Kanaya, Y., Shimizu, A., Aoki, K., and Akimoto, H.: Atmospheric aerosol variations at Okinawa Island in Japan observed by MAX-DOAS using a new cloud-screening method, J. Geophys. Res., 114, D18213, doi:10.1029/2009JD011939, 2009.

Vaisala Oyj: Ceilometer LD40 User's Guide, Document M210256en-DJ, Vaisala Oyj, Helsinki, 2006. van Loon, M., Vautard, R., Schaap, M., Bergstrom, R., Bessagnet, B., Brandt, J., Builtjes, P., Christensen, J., Cuvelier, C., Graff, A., Jonson, J., Krol, M., Langner, J., Roberts, P., Rouil, L., Stern, R., Tarrason, L., Thunis, P., Vignati, E., White, L., and Wind, P.: Evaluation of long-term ozone simulations from seven regional air quality models and their ensemble, Atmos. Environ., 41, 2083-2097, doi:10.1016/j.atmosenv.2006.10.073, 2007.

Vandaele, A. C., Hermans, C., Simon, P. C., Carleer, M., Colin, R., Fally, S., Merienne, M. F., Jenouvrier, A., and Coquart, B.: Measurements of the NO2 Absorption Cross-section from $42000 \mathrm{~cm}^{-1}$ to $10000 \mathrm{~cm}^{1}(238-1000 \mathrm{~nm})$ at $220 \mathrm{~K}$ and $298 \mathrm{~K}$, J. Quant. Spectr. Ra., 59, 171-184, 1998.

Vlemmix, T., Piters, A. J. M., Stammes, P., Wang, P., and Levelt, P. F.: Retrieval of tropospheric $\mathrm{NO}_{2}$ using the MAX-DOAS method combined with relative intensity measurements for aerosol correction, Atmos. Meas. Tech., 3, 1287-1305, doi:10.5194/amt-31287-2010, 2010.

Vlemmix, T., Piters, A. J. M., Berkhout, A. J. C., Gast, L. F. L., Wang, P., and Levelt, P. F.: Ability of the MAX-DOAS method to derive profile information for $\mathrm{NO}_{2}$ : can the boundary layer and free troposphere be separated?, Atmos. Meas. Tech., 4, 26592684, doi:10.5194/amt-4-2659-2011, 2011.

Volten, H., Brinksma, E. J., Berkhout, A. J. C., Hains, J., Bergwerff, J. B., Van der Hoff, G. R., Apituley, A., Dirksen, R. J., Calabretta-Jongen, S., and Swart, D. P. J.: $\mathrm{NO}_{2}$ Lidar Profile Measurements for Satellite Interpretation and Validation, J. Geophys. Res.-Atmos., 114, D24301, doi:10.1029/2009JD012441, 2009.

Wagner, T., Beirle, S., Brauers, T., Deutschmann, T., Frieß, U., Hak, C., Halla, J. D., Heue, K. P., Junkermann, W., Li, X., Platt, U., and Pundt-Gruber, I.: Inversion of tropospheric profiles of aerosol extinction and $\mathrm{HCHO}$ and $\mathrm{NO}_{2}$ mixing ratios from MAX-DOAS observations in Milano during the summer of 2003 and comparison with independent data sets, Atmos. Meas. Tech., 4, 2685-2715, doi:10.5194/amt-4-2685-2011, 2011.

Wauben, W., Klein Baltink, H., de Haij, M., Maat, N., and The, H.: The status, evaluation and new developments of the automated cloud observations in the Netherlands, (presented at) Technical Conference, World Meteorol. Org., Geneva, Switzerland, IOM 94(TD 1354), http://www.wmo.int/pages/prog/www/IMOP/publications/ IOM-94-TECO2006/1(7)_Wauben_Netherlands.pdf (last acces: December 2014), 2006.

Wittrock, F., Oetjen, H., Richter, A., Fietkau, S., Medeke, T., Rozanov, A., and Burrows, J. P.: MAX-DOAS measurements of atmospheric trace gases in Ny-Ålesund - Radiative transfer studies and their application, Atmos. Chem. Phys., 4, 955-966, doi:10.5194/acp-4-955-2004, 2004. 